\title{
Design of a new energy dissipating device and verification for use in rockfall protection barriers
}

\author{
Castanon-Jano Laura, Blanco-Fernandez Elena, Castro-Fresno Daniel \\ GITECO Research Group. University of Cantabria. Santander. Spain.
}

\begin{abstract}
Flexible barriers are structures used to protect specific areas from falling rocks. In most cases, barriers have energy dissipating devices (or brakes), that help to increase their energydissipation capacity by deformation, friction or the two mechanisms together. One drawback that has been detected in existing brakes is that they usually display irregular behaviour so that their real performance can present unexpected results in terms of activation force or total energy absorbed. This paper presents the complete design procedure of a new brake, which is proposed as a potential alternative to solve these uncertainties. The main energy dissipation mechanism is by plastic deformation of its components. The design procedure combines experimental tests and numerical modelling to take advantage of the benefits of both techniques. The final geometry is selected considering its efficiency, which involves not only total absorbed energy, but also energy absorbed per unit of mass.
\end{abstract}

\section{Keywords}

Brakes, flexible barriers, numerical FEM modelling, experimental tests, design process

\section{Introduction}

When a system to protect a specific zone from falling rocks has to be designed, several alternatives are feasible depending on the block size, speed and frequency of the rockfalls $[1,2]$. Among all of the possibilities, flexible barriers are suitable structures for a wide range of energies $[3 ; 4]$ and a medium level of recurrence and they are in high demand because of their low cost and easiness of set up. These barriers are composed of an interception structure whose position is ensured by mean of posts, forming modules with a certain angle with the slope. Perimeter cables help to keep the membrane erected and to transmit the loads to the ground, as they are fixed to it at both ends. The posts are connected to the ground with base plates, and the connection can be fixed [5] or hinged [6]. In the latter case, upstream cables are needed to limit the displacement of the free end of the posts. In some cases, energy dissipating devices are used in the upstream and the perimeter cables. These devices, also called brakes, work by different mechanisms -mainly deformation, partial failure, friction or mixed- to dissipate part of the energy coming from an impact on a barrier [7]. Hence, with their inclusion, the absorption capacity of the barrier can substantially increase in comparison to the same barrier without any of them.

The creation of a brake is a process that requires first the development of an idea to be implemented later in an initial design. Experimental tests are mandatory for successful results in the new design, since they allow the complete behaviour and the weak points of the brake to be accurately known. However, their combination with numerical finite element modelling (FEM) is essential to reduce costs and optimize the geometry. 
The study of new brake elements has been carried out by several authors using different strategies. Trad A. $2011 \mathrm{PhD}$ thesis [8] explained the complete design process of his brakes, but in that case only experimental tests were done. His work was focused on the description of the full experimental procedure until achieving a final solution to be used in a real barrier. In the same line, Fulde et al., 2013 [9] developed a spiral brake and improved its geometry by means of experimental quasi-static tests of different modifications from the initial design. Other studies were related with the behaviour analysis and characterization of brakes -in a static or dynamic way-, such as Peila et al., 1998 [10], Tran et al., 2012 [11] and Wang et al 2016 [12]. The most recent work was carried out by Wang et al. 2019 [13]. It takes a tube-crushing dissipator as a reference and improves its geometry by modifying it making it symmetric. The common thing in all the works mentioned above is that they use experimental tests as their only support tool. The only work found that takes advantage of the FEM for finding improvements on the design was Castro-Fresno et al 2009 [14], finding that a shortening of the pipes that form the double $U$ brake would ensure its integrity and a correct performance.

In this work, the final solution is also aimed at reaching a regular behaviour at least in static conditions, where the application of the load is completely controlled. The installation of brakes with an irregular behaviour on flexible barriers would negatively affect the total behaviour of the complete structure, since a previous activation of the brakes from the expected could happen, as well as a premature wearing out due to a lower absorption energy that could lead to higher loads on the cables in which the brakes are installed.

An initial study of the different dissipation mechanisms was done and some of them were discarded due to their potential problems. That is the case of friction brakes, which could reach different behaviour curves on for 3 similar samples, as in the case of brakes of double tube in $U$ [14] (Figure 1a), or present a reduction of force after its activation, as in cases of loop brake [15] or double friction brake [16] (Figures $1 \mathrm{~b}$ and 1c). Besides that, the rusting of the materials completely modifies the behaviour of the brake with a rougher surface and a more fragile material which could mean a premature break, like what happens in Figure 1d on ring brakes, found by [16].
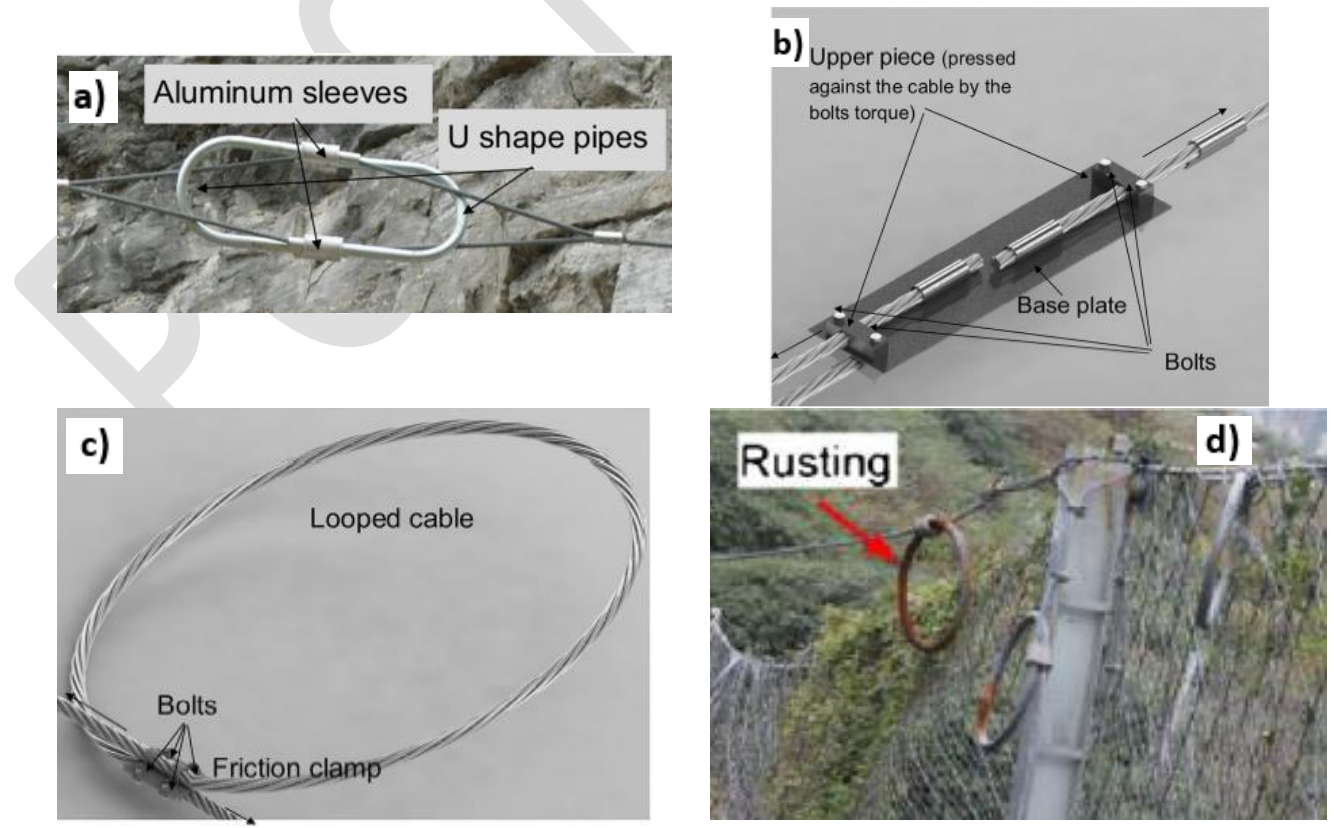

Figure 1. Friction and mixed friction-deformation brakes: (a) brake with double tube in $\mathrm{U}$ (Source: [7]), (b) double friction brake (Source:[7]), (c) loop brake (Source: [7]) and (d) rusting on a ring brake (Source: [16]). 
Buckling was discarded due to the difficulty of creating a new brake using this concept, since many versions already exist: with one squared tube and only one continuous cable; an asymmetric brake with two tubes and two cables, and the newest one removing the asymmetry and adding two tubes (Figure 2). The creation of a new brake under these conditions would only be possible by adding a higher complexity to the geometry, what would mean an increase on the cost.
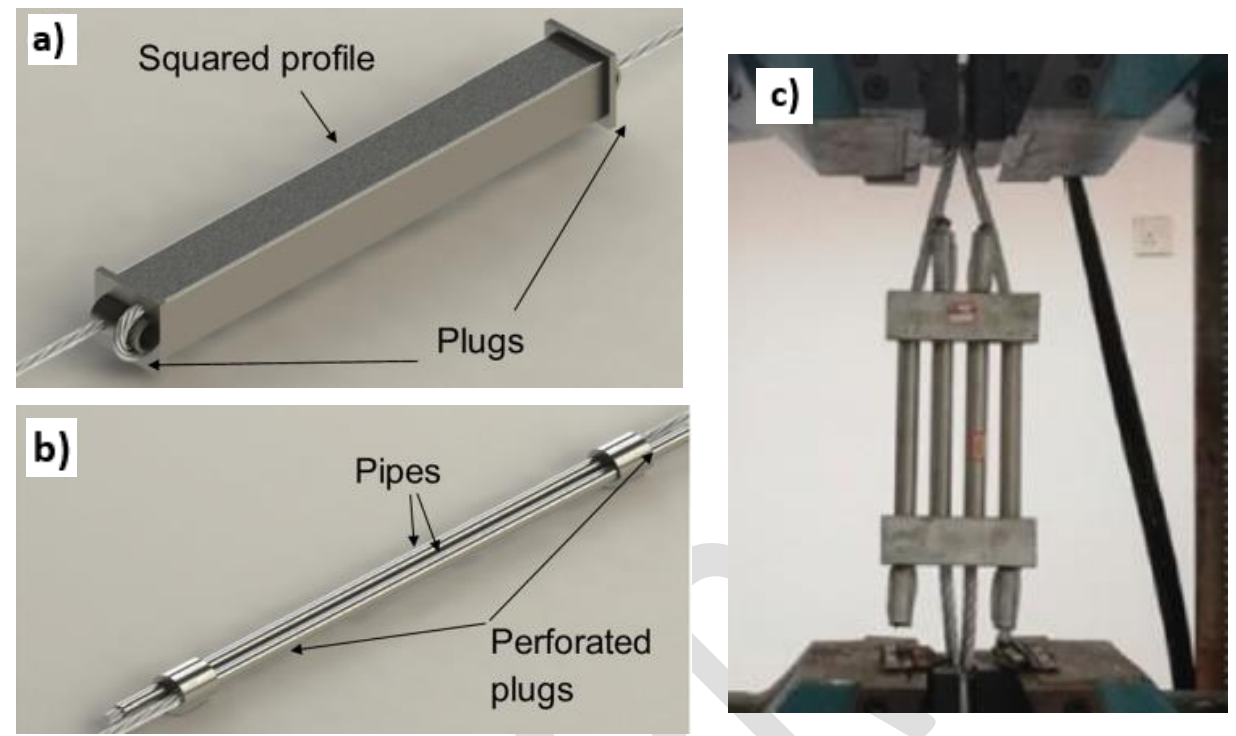

Figure 2. Brakes working by buckling: (a) square profile brake (Source: [7]), (b) double tube brake (Source: [7]) and (c) symmetric tube-crushing (Source: [13]).

\section{Design description}

The new design is shown in Figure 3 and is based on the plastic deformation of its components [18]. It is composed of a series of hollow profiles disposed one after the other. Each profile has four holes where the main cables go through. The aligned profiles finish in both sides with two plugs with greater thickness than the profiles. The main cables are inserted through the holes from opposite ends and in opposite directions, and after crossing through all the pieces, they are locked with two consecutive aluminium caps which are fixed to the cables by applying pressure to them. Inside a barrier, the brake must be replaceable in case its energy-dissipation capacity is exhausted. Thus, each brake has two cables which are independent from the lateral and upstream cables of the barrier in which they are installed. The cables of the brake end in a loop, which enables easy installation or substitution by using shackles to connect them to the cables of the barrier. Finally, a safety cable was included in the design and connected to the ends of the main cables of the brake. The length of this safety cable must be sufficient to allow the brake to completely elongate without obstructing its path. If a main cable breaks, the safety cable ensures the continuity of the cable in which the brake is installed and avoids the failure of the barrier.

The impact of the block on a flexible barrier makes the aluminium caps located in the main cables of the brake press the perforated plugs in opposing directions compressing the circular profiles and dissipating energy by deformation and friction among the components. 


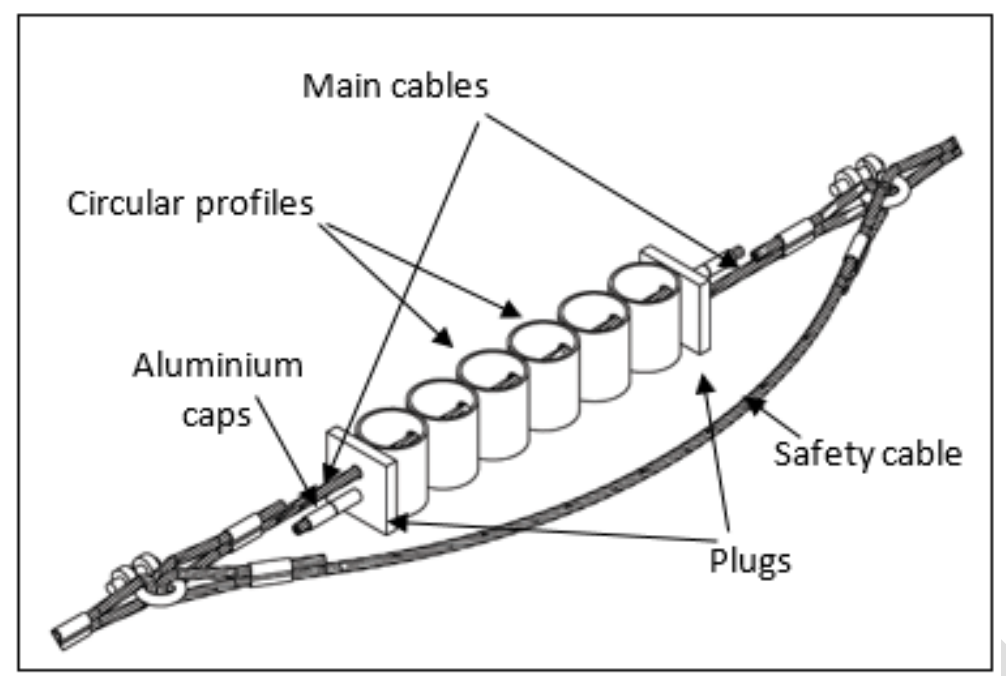

Figure 3. New brake design and parts.

The design has been created considering four essential aspects: integrity, adaptability, durability and service limit state [6]. The integrity of the brake, which means prevention of its complete break into two parts that could cause further damage in the structure, has been ensured using the safety cable described before. This brake design also fulfils the adaptability aim, since tubes with different diameters and thickness can be used depending on the energy to be absorbed. Moreover, the number of tubes is a parameter that influences the maximal elongation, and hence, the energy-dissipation capacity, making the brake adaptable to different cases. The use of stainless steel for all the elements of the brake increases the durability and resistance to the harshness of the climate. Finally, the service limit state, meaning the ability of the brake to resist several impacts, is fulfilled since the tubes can partially deform if the energy is not high enough, so in a next impact the brake would have a residual capacity to absorb energy.

\section{Initial FEM approach}

The first action after the design idea is to find out whether the energy absorption mechanism works well, and the manufacturing of the brake is feasible. If the first FEM models demonstrate that the brake is suitable to dissipate energy, they will be helpful to find out the energy impact that should be applied on the dynamic tests, which is the next step in the design. In addition, the initial numerical models can also show deficiencies on the first geometry design that could be solved before carrying out any experimental test with the subsequent save of money.

The first numerical model is created in the most simplified way, using Ansys Workbench software in the Static Structural module, focused on quasi-static behaviour [19].

The model created has 5 tubes of $101.6 \mathrm{~mm}$ diameter, $5 \mathrm{~mm}$ thickness and a $120 \mathrm{~mm}$ length. The steel used for the tubes is $S 355 \mathrm{JR}$, with a density of $7850 \mathrm{~kg} / \mathrm{m3}$, a Young Modulus of 210 $\mathrm{GPa}$, a yield stress of $360 \mathrm{MPa}$ and a tangent modulus (plastic slope of the stress-strain curve) of 1311.2 MPa. The plasticity was included by means of a Bilinear Isotropic Hardening model. The plugs are two square plates of dimensions $20 \times 120 \times 25 \mathrm{~mm}$. The cables go through the aligned holes of all the components in opposite directions and are physically linked to one plug each, to avoid the need to include the aluminium caps in the model, since they have the same effect in a more simplified way. Moreover, the cables and the plugs are simplified giving them rigid 
material properties. All these features help the model convergence. Due to the material properties mentioned before the only elements of the model able to dissipate energy by deformation are the tubes. The lower plug is fixed, and a prescribed displacement of $350 \mathrm{~mm}$ is given to the upper plug towards the lower one, inducing the compression of all the tubes. The friction coefficient between all the components of the model is 0.2 , the usual steel-steel coefficient found in the literature. The hexagonal mesh size is $1.6 \mathrm{~mm}$, with an automatic refinement in the areas with a higher curvature. Symmetry was included in the model, which helps to reduce the computational cost.

As seen in Figure 4 (right) the tubes compress and absorb energy by deformation, adopting a $\infty$ shape. This happens because the upper and lower part of the tubes are weakened by the holes where the cables go through.

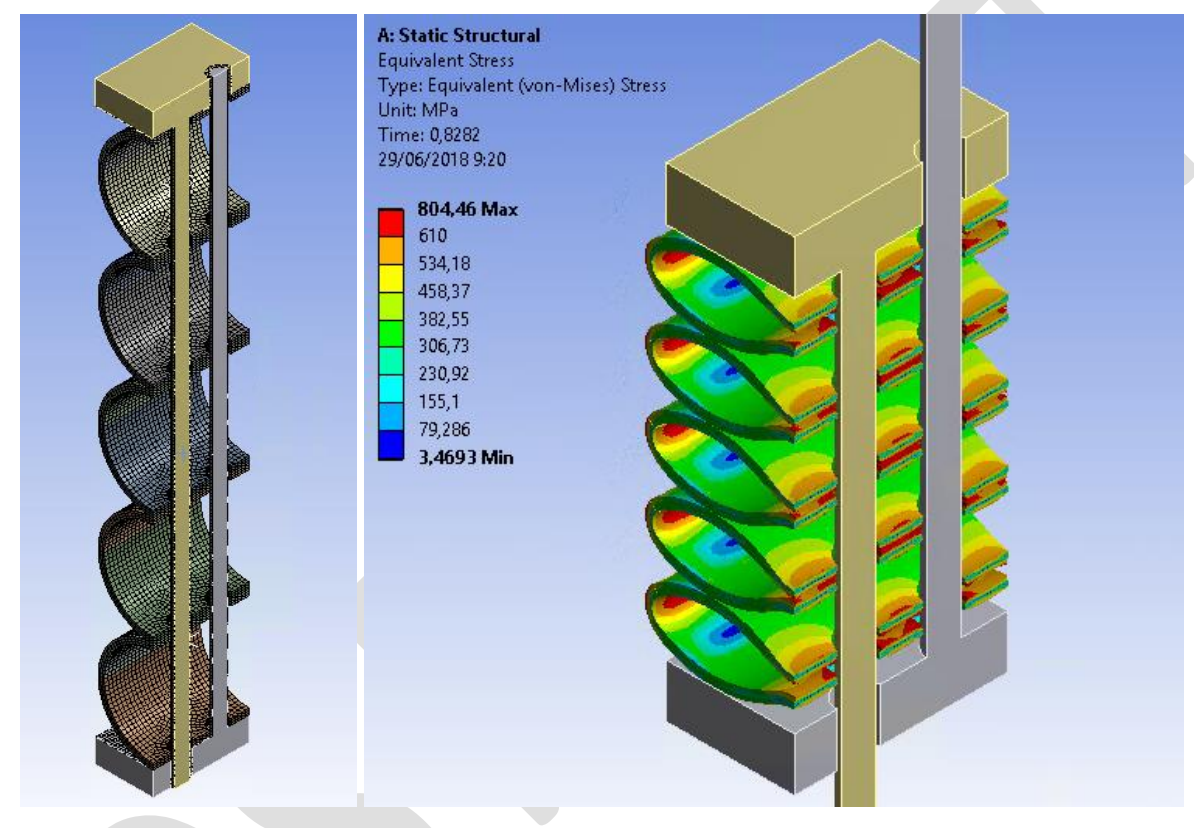

Figure 4. Geometry, mesh and equivalent stress of the initial FEM model of the brake.

The squashing of the tubes causes deformation of the holes, which could lead to "throttling" or "clamping" of the cables, impeding their free movement and disabling the brake function. Figure 5 shows that with a $5 \mathrm{~mm}$ thick tube, the gap between the cable and the hole is only $0.35 \mathrm{~mm}$. For tubes with a higher thickness this behaviour could be aggravated until the brake stops working. The first idea to solve this problem was to directly increase the diameter of the holes. However, this leads to a quick decrease in the resistance force, and, hence, of energy-dissipation capacity. For this reason, henceforth, it was decided to enlarge the holes in the perpendicular direction to the thickness of the tubes (Figure 5). 
a)

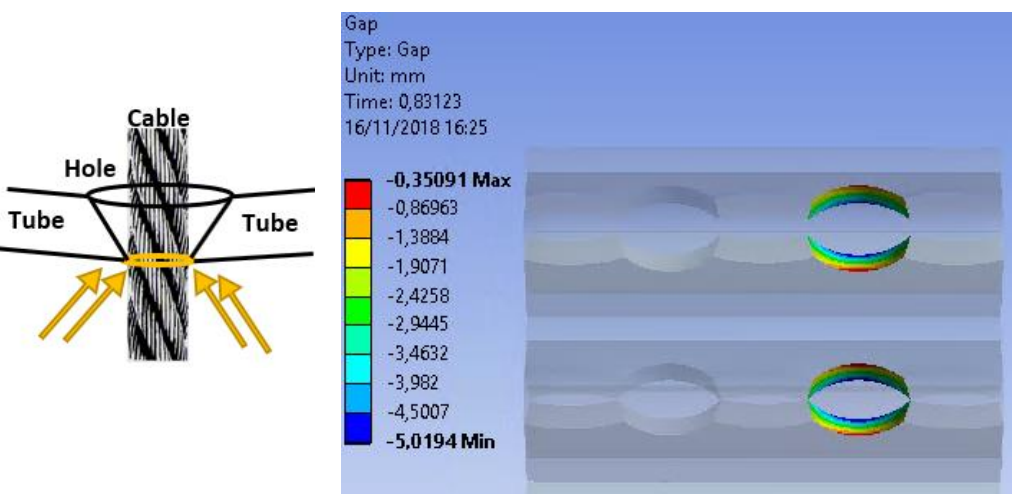

c)

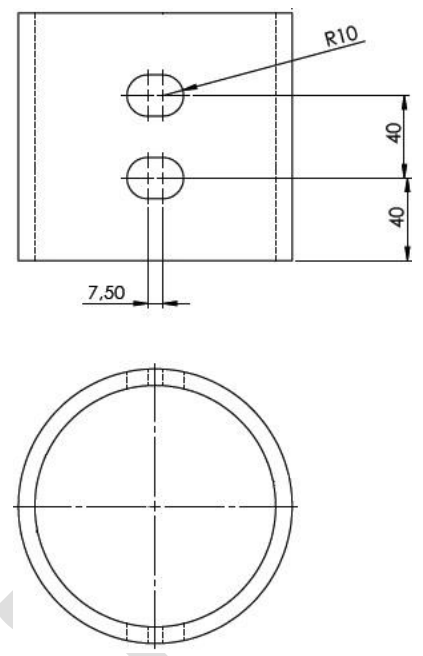

Figure 5. Narrowing of the holes of the tube that could cause clamping of the brake cables.

The equivalent stress of the model is higher than the ultimate strength of the material (744 $\mathrm{MPa}$ ), so cracks could appear in the model and the damaged zones, located in the red areas of Figure 4, would not contribute to the stress transmission. Due to the high nonlinearity of the model (plasticity and in some cases until rupture) it was decided to turn the model into an Explicity Dynamic module of Ansys, which can deal better with these features. In this module, the computational time is calculated slightly differently, since it is related to the element size instead of to the number of elements, as happens in the static module. Consequently, the number of tubes was reduced to two. A material damage model was included, so the elements disappear once the stress overcomes the ultimate strength of the material and stop transmitting energy to the rest of the tube. The failure of the elements was included using the option Plastic Strain Failure, with a strain value of 0.19532 . Friction coefficients and boundary conditions keep the same as the static model. The mesh was changed into tetrahedral shape elements due to an hourglassing problem (see more details in section 5), keeping 3 elements per thickness. The computational time was reduced from 64.7 hours on the static simulation with 5 tubes to 6.6 hours on the explicit simulation with two tubes. In Figure 6 the results are shown in terms of equivalent stress after applying a $170 \mathrm{~mm}$ displacement to the upper plug. The lateral part of the tubes has lost some of its elements due to the surpassing of the ultimate strength of the material.

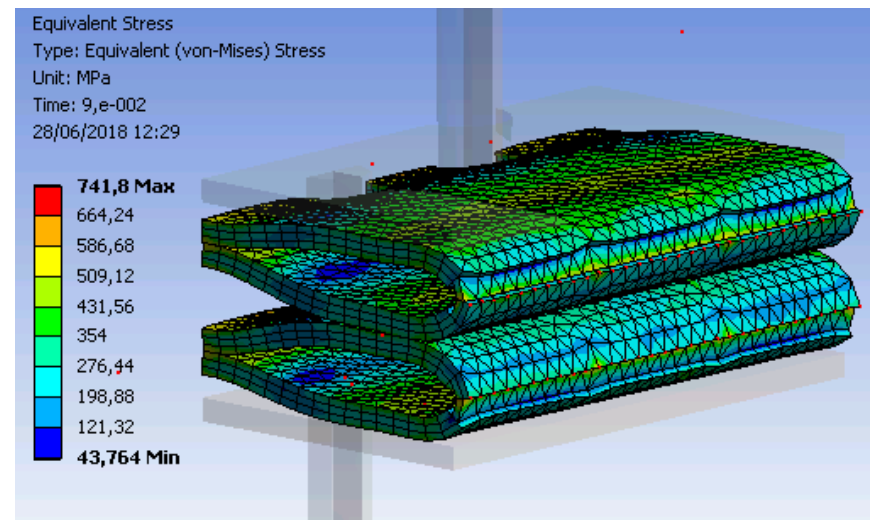

Figure 6. FEM simulation of a 2-tube brake in the explicit module, including a damaged material model. 


\section{Experimental campaign}

To corroborate that the new design has correct behaviour both dynamic and quasi-static tests were performed.

\subsection{Dynamic tests}

These dynamic tests were performed first, since they better represent the load application (impact load) with respect to reality. The configuration of the test is type 1 of the classification on [6], which is a mass dropping system. The other two configurations were discarded since they require more complex and expensive infrastructures, in one case, a specific frame for the test and, in the other, the building of an entire barrier.

The literature found in which type 1 tests are performed [20] shows an open-air location, with a vertical $80 \mathrm{~m}$ high wall. In this location, the energy passed to the brake could reach $600 \mathrm{~kJ}$ with a 3-ton mass and a drop height of $20 \mathrm{~m}$. In this case, in an initial development phase, high energies are not needed. The tests are performed in lower scale brakes using a $4.9 \mathrm{~m}$ high frame.

The test scheme can be seen in Figure 7. A steel sling is located around the horizontal beam of the frame and is closed with a high resistance shackle. Its aim is to act as a fixed point in an elevated position for one end of the brake. On the other end a $465 \mathrm{~kg}$ mass is suspended, fixed with another shackle. To elevate the mass, a bridge crane is used. The device used to let the mass drop is a hook with two holes; the upper one for the connection with the bridge crane and the lower one for the shackle connecting the mass and the brake. The hook has a lever that can be activated with a long extension rope, opening the lower hole and freeing the mass. Since the lever is in an inverted position, a pole is needed to apply the force needed. The hook has a locking device to avoid accidental release.
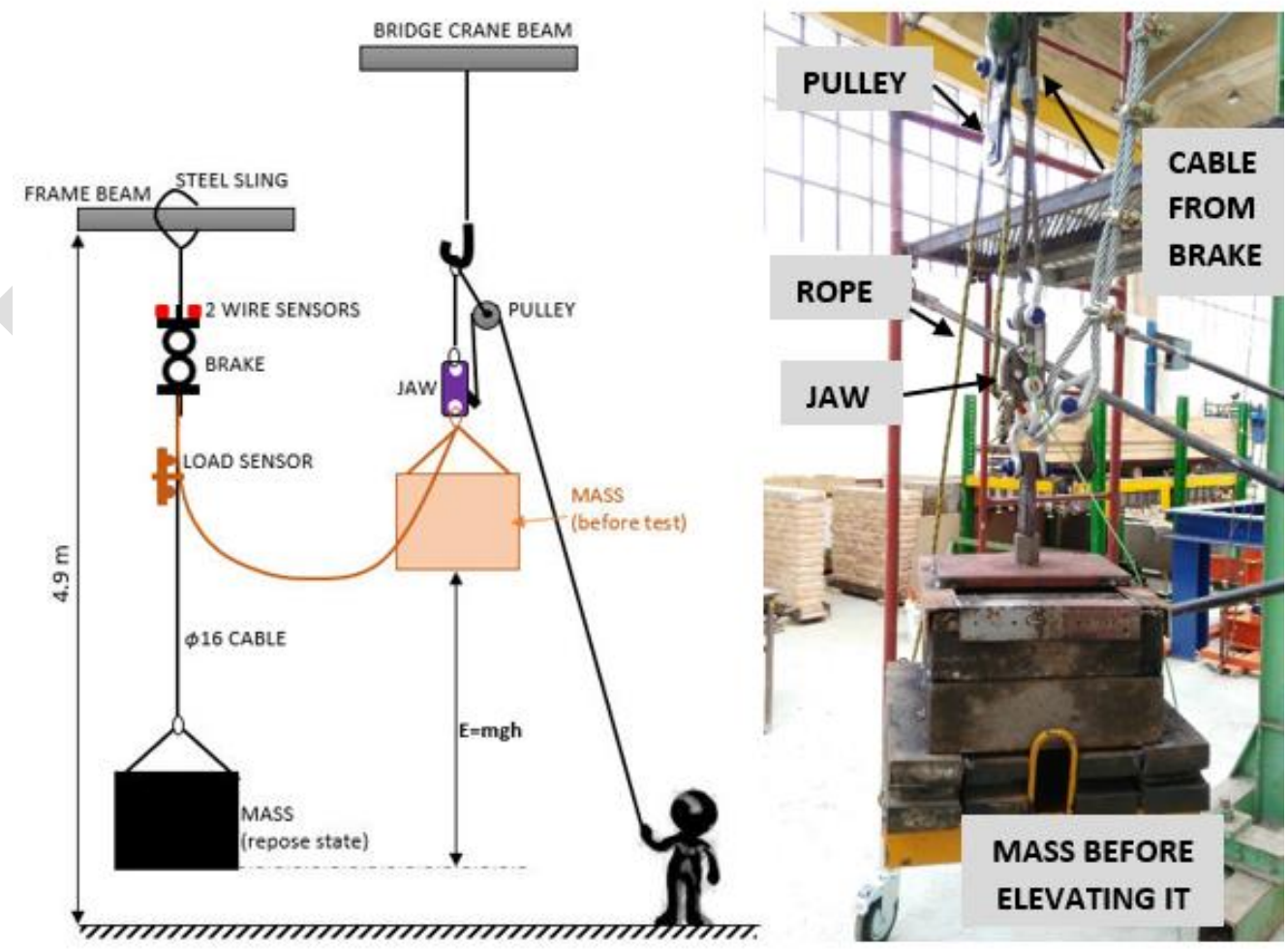

Figure 7. Scheme of the dynamic test configuration. 
To know the cable load, and, hence, the compression load on the tubes at any point of time, a force measurement device is used [23; 3]. The data frequency is $5000 \mathrm{~Hz}$. The compression length is measured using two wire sensors located on the upper plug, and with the wire connected to the lower plug. The compression length in the central zone is the average of the measurements of the two wire sensors. The data acquisition equipment was a DEWE 43A [22].

Four types of brakes are tested, in which the number and the dimensions of the tubes are varied (Table 1). Although the number of tubes in the final design of the brake is foreseen to be higher, the brakes to be tested are scaled due to the limitations of height and mass.

Table 1. Number and dimensions of the tubes of the four brakes dynamically tested.

\begin{tabular}{|c|c|c|c|c|}
\hline & No tubes & $\begin{array}{c}D_{\text {ext }} \\
(\mathrm{mm})\end{array}$ & $\begin{array}{c}\text { Thickness } \\
(\mathrm{mm})\end{array}$ & $\begin{array}{c}\text { Length } \\
(\mathrm{mm})\end{array}$ \\
\hline Brake 1 and 3 & 2 and 3 respectively & 101,6 & 5,0 & 120 \\
\hline Brake 2 and 4 & 2 and 3 respectively & 114,3 & 6,3 & 120 \\
\hline
\end{tabular}

The energy applied on the impact is selected from dynamic numerical simulations performed on the previous section (Figure 6), and it is preferable to avoid rupture of the tubes, since small parts could fly off uncontrollably causing personal injury. Hence, the energy levels selected for the dynamic tests are those reached before ruptures appear in the numerical model. The aim of this dynamic tests is to find out whether these devices work properly in real conditions; that is, with impact loads. In the next section of this work quasi-static tests are shown and brakes are controllably tested up to their ultimate strength. The deformation state and Von Mises stress of each numerical model before rupture are shown in Figure 8.

Although the energy used in the simulations corresponds to the deformation of the tubes, it is known that cables also absorb a certain part of the energy by elastic deformation, which the system will recover in the rebound. Although the energy applied could be increased due to this fact, the same energy as in the simulations was used as a safety factor.

The energy is applied to the system by controlling the height of the mass with respect to the rest position, using the equation $e=m g h$. The impact speed is calculated using the equation $v=$ $\sqrt{2 g h}$. The energy applied to the system, the height and speed, and the energy absorbed by the tubes are shown in Table 2. The Force-Displacement curves are displayed in Figure 9.

In test $\mathrm{n}-1$, the wire sensors detached and flew off so results could not be obtained. To solve this problem, the fixation was reinforced, and wire sensors were screwed to two "L-shaped" profiles welded to the upper plate (Figure 8).

It can be also noted that in dynamic test $\mathrm{n}-2$ the displacement was not obtained averaging the two wire sensors, since one of them was damaged during the test. That is why the initial slope of the green curve does not follow the same trend as the others.

As expected, the tubes did not deform in the same way as in the simulations due to the simplifications of the numerical models that considered the tubes to be the only deformable pieces. The last column of Table 2 shows the percentage of absorbed energy related to the energy applied to the system. The absorbed energy is calculated integrating the load- 
displacement curve obtained from the record of the load cell and the average of the compression measured by the wire sensors. The plastic deformation of the tubes only represents between 25 and $67 \%$ of the energy applied to the system. The remaining energy corresponds to the elastic and plastic deformation of the cables, the friction of the cables among themselves and with the accommodation of cable ties, and the friction of the cables and the plugs due to the eccentricity of the brake.

The activation force of the brakes is $25 \mathrm{kN}$ for type 1 , and around $45 \mathrm{kN}$ for type 2 . In brakes type 3 and 4, activation forces were between 20 and $38 \mathrm{kN}$ in type 3 and between 46 and $55 \mathrm{kN}$ in type 4 . Figure 8 shows the final state of the brakes after the test.

The dispersion on the results of activation force is thought to be due to the load sensor could acquire an incorrect position on the cable. This is because at the beginning of the test, the cable in which the sensor is located is not in a straight position, but slightly curved. The sensor, by its own geometry, gets fixed in the cable when the cable is straight, but can slide and move when it is slightly bended, since there is zero tension [2]. Test number 7 seems to have an extremely high dispersion, since the activation force is excessively far from the activation forces with the same tube types, which could have close values. For this reason, this test could be discarded.

Concerning the rest of the dynamic tests, a slight dispersion is considered to be normal, such as the found on the activation force of brakes 3 and 4 (excepting test 7), since the force is not completely controlled, and the dynamics of the whole plays an unknown role for the moment. However, these tests were mainly carried out to see if they have a correct behaviour under dynamic conditions. The load-displacement curves (that is, the behaviour curves) will be extracted from the static tests.

Table 2. Impact test parameters and energy absorbed by the tubes of the brakes.

\begin{tabular}{|c|c|c|c|c|c|c|c|}
\hline & $\begin{array}{c}\text { Test } \\
\text { no }\end{array}$ & $\begin{array}{c}\text { Energy } \\
\text { applied } \\
\text { (kJ) }\end{array}$ & $\begin{array}{l}\Delta h \\
\text { (m) }\end{array}$ & $\begin{array}{l}\text { Impact } \\
\text { speed } \\
(\mathrm{m} / \mathrm{s})\end{array}$ & $\begin{array}{l}\text { Activation } \\
\text { force } \\
(\mathrm{kN})\end{array}$ & $\begin{array}{l}\text { Energy } \\
\text { absorbed } \\
\text { by the } \\
\text { tubes }(\mathrm{kJ})\end{array}$ & $\begin{array}{l}E_{\text {abs }} \\
/ E_{\text {apli }}\end{array}$ \\
\hline \multirow{3}{*}{ Brake 1} & 1 & \multirow{3}{*}{5.4} & \multirow{3}{*}{1.18} & \multirow{3}{*}{4.8} & & - & - \\
\hline & 2 & & & & 23.5 & 1.990 & 0.368 \\
\hline & 3 & & & & 25 & 2.368 & 0.430 \\
\hline \multirow{3}{*}{ Brake 3} & 7 & \multirow{3}{*}{8.3} & \multirow{3}{*}{1.78} & \multirow{3}{*}{5.9} & 38.4 & 5.618 & 0.676 \\
\hline & 8 & & & & 20 & 4.743 & 0.571 \\
\hline & 9 & & & & 24 & 4.422 & 0.532 \\
\hline \multirow{3}{*}{ Brake 2} & 4 & \multirow{3}{*}{7.5} & \multirow{3}{*}{1.62} & \multirow{3}{*}{5.6} & 49 & 2.535 & 0.330 \\
\hline & 5 & & & & 43.8 & 1.937 & 0.258 \\
\hline & 6 & & & & 43.7 & 2.943 & 0.392 \\
\hline \multirow{3}{*}{ Brake 4} & 10 & \multirow{3}{*}{12.5} & \multirow{3}{*}{2.71} & \multirow{3}{*}{7.28} & 54 & 6.042 & 0.483 \\
\hline & 11 & & & & 46 & 5.816 & 0.465 \\
\hline & 12 & & & & 55 & 7.102 & 0.568 \\
\hline
\end{tabular}




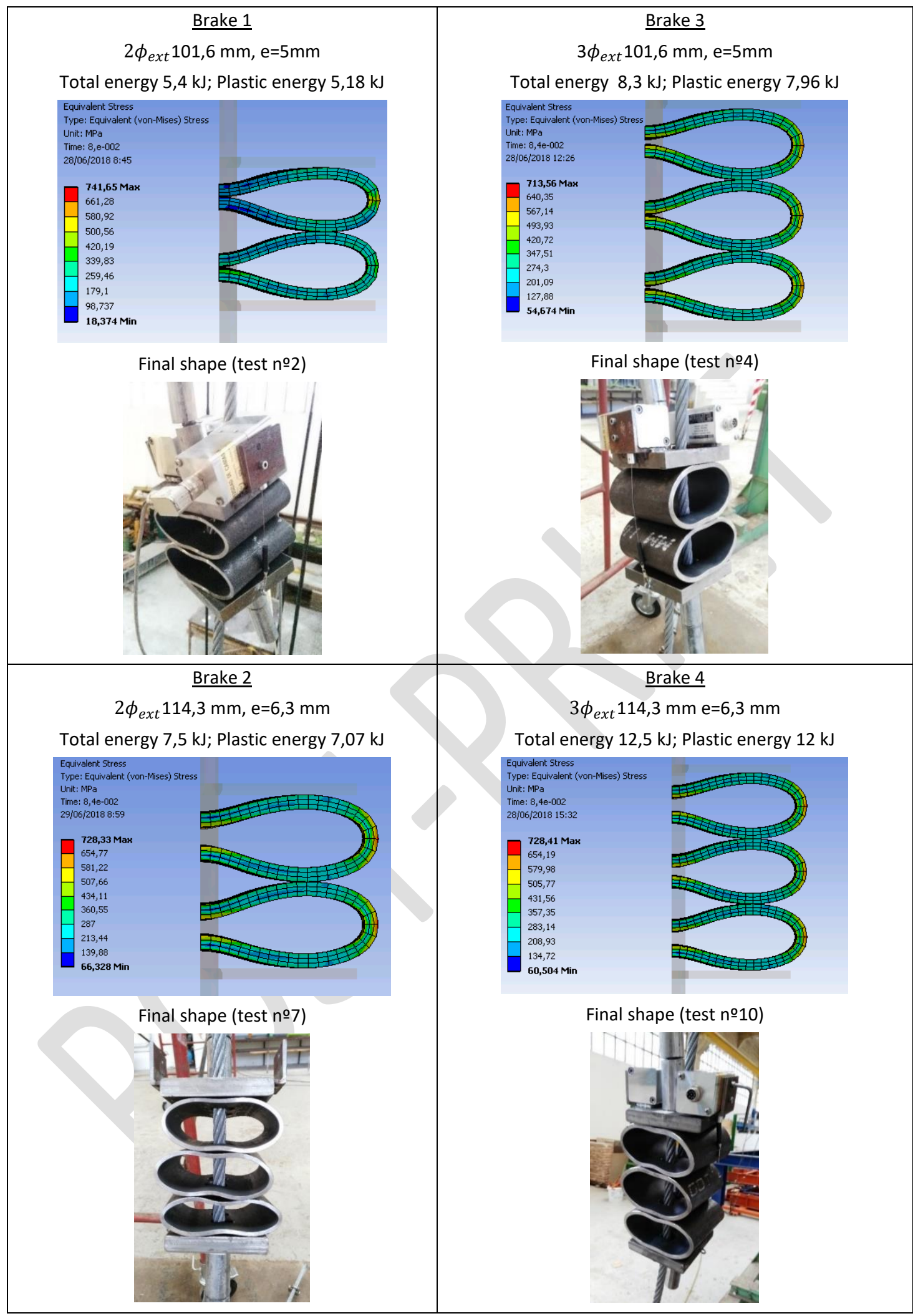

Figure 8. Deformed shape and energy absorbed by the tubes on the numerical simulations of the brakes and final appearance of 4 brakes (one of each type) dynamically tested. 

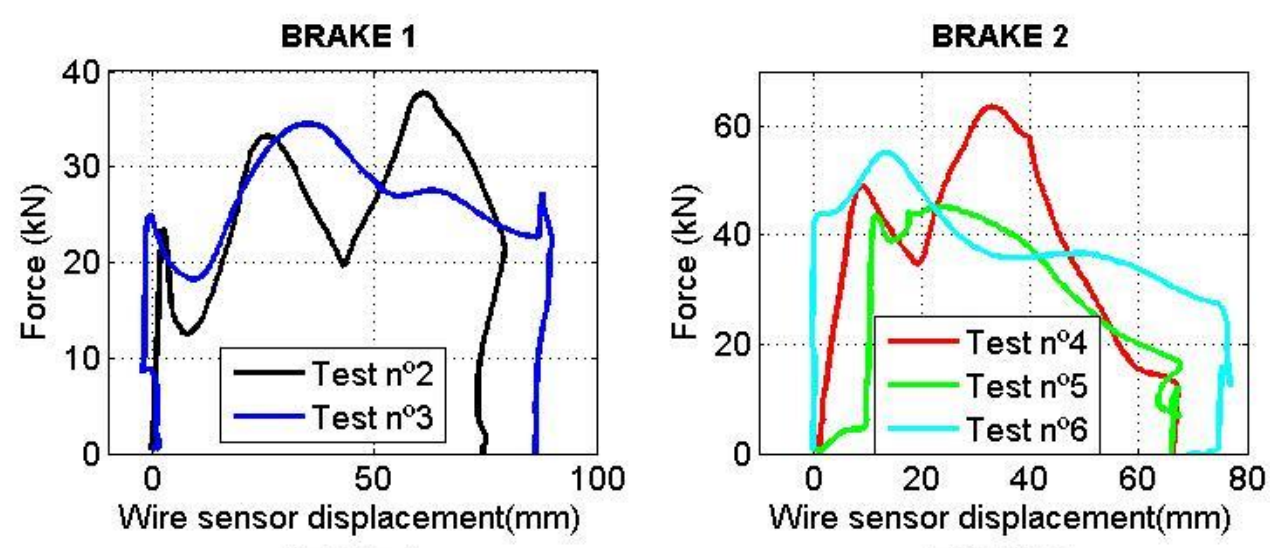

BRAKE 3
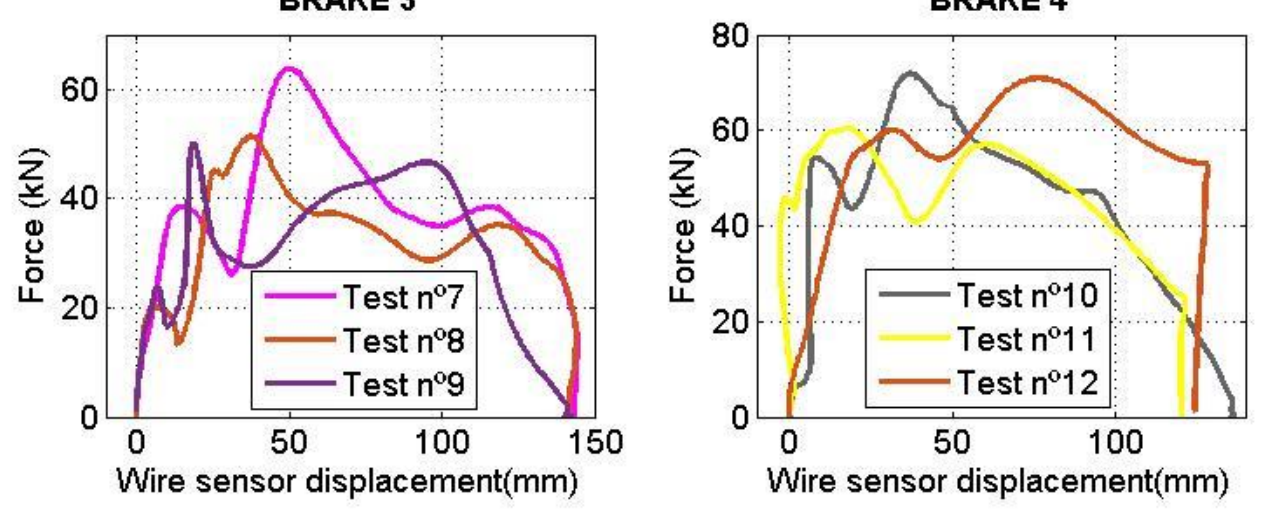

Figure 9. Force-displacement curves obtained in the dynamic test

\subsection{Quasi-static tests}

The performance of the dynamic test demonstrated that there are multiple variables that are very difficult to control: the friction of the steel sling with the horizonal beam of the structure, the rebound of the mass after the first impact with its unpredictable energy recovery or the friction of the cables with the upper and lower plugs.

With the aim of removing all these uncertainties, quasi-static tests on brake type 1 , as well as quasi-static tests on cables and compression tests on independent tubes were performed.

\section{- Cables}

6 samples of cable of type $7 \times 19$ with a diameter $16 \mathrm{~mm}$ and a length of $680 \mathrm{~mm}$ from two different suppliers were quasi-statically tested with a speed of $0.1 \mathrm{~mm} / \mathrm{s}$. Figure 10 shows that, in most cases, the breakage was in one or more strands, except in case 3 that broke completely into two parts.

Cables show two different behaviours. Samples 1, 2 and 3 show a higher yield stress and lower ultimate strength than samples 4, 5 and 6 . Furthermore, the latter present an identical loaddisplacement curve whilst in cables 1, 2 and 3 there is more variability after reaching the yield stress. Despite all this, the absorbed energy in all the samples was similar. The only atypical behaviour took place in cable 1 , with a premature breakage, probably due to the deterioration of wire during storage or manipulation. 

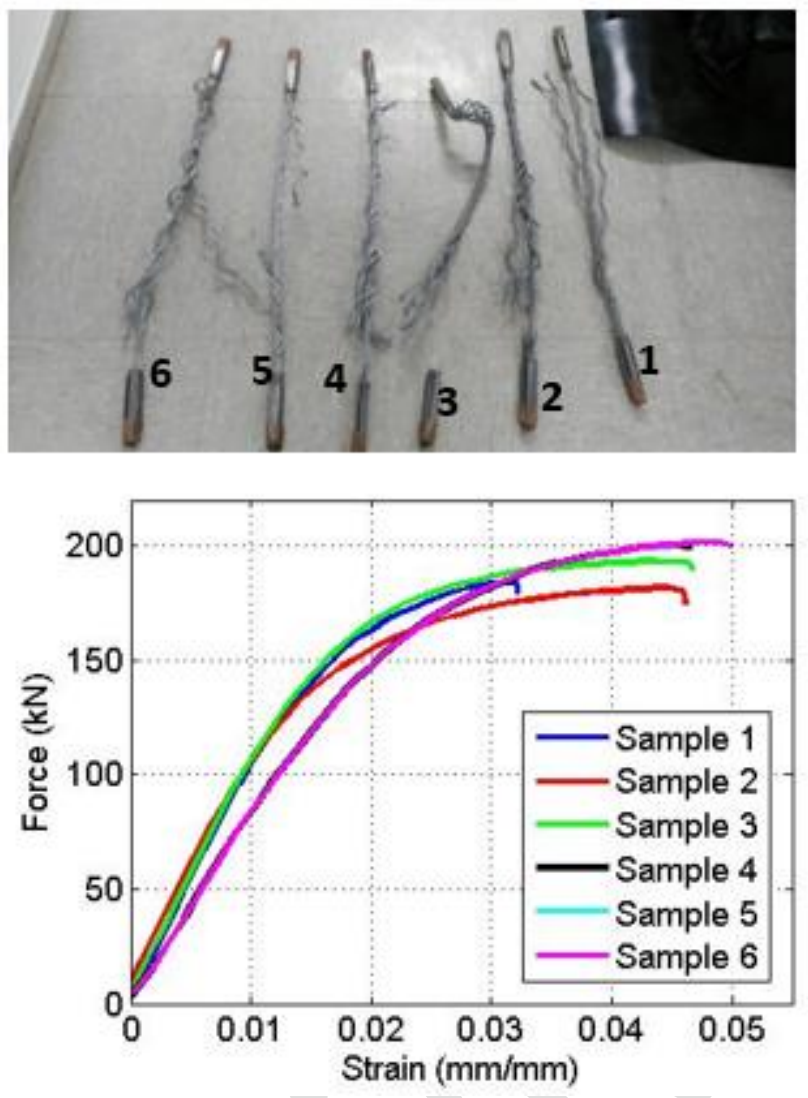

Figure 10. Appearance of the cables after the quasi-static tests (above) and force-strain graph of all the samples tested.

Table 3. Force at failure $\left(F_{u}\right)$, tensile strength, and absorbed energy of the quasi-static tests in $\phi 16 \mathrm{~mm}$ cables.

\begin{tabular}{|c|c|c|c|c|}
\hline $\begin{array}{c}\text { Cable } \\
\text { № }\end{array}$ & Type & $\begin{array}{c}\text { Tensile } \\
\text { strenght } \\
(\mathrm{MPa})\end{array}$ & $\mathrm{F}_{\mathrm{u}}(\mathrm{kN})$ & $\begin{array}{c}\text { Energy } \\
(\mathrm{kJ})\end{array}$ \\
\hline 1 & $7 \times 19$ & 1658.7 & 184.12 & 2.76 \\
\hline 2 & $7 \times 19$ & 1643.6 & 182.44 & 4.40 \\
\hline 3 & $7 \times 19$ & 1743.1 & 193.49 & 4.72 \\
\hline 4 & $7 \times 19$ & 1817.8 & 201.78 & 4.47 \\
\hline 5 & $7 \times 19$ & 1811.8 & 201.11 & 4.43 \\
\hline 6 & $7 \times 19$ & 1827.5 & 202.85 & 4.92 \\
\hline
\end{tabular}

- Tubes

A laboratory machine was adapted to perform compression tests on tubes. To prevent accidents related to sliding of the tube, the test area was surrounded by a plastic net. The test speed was $1 \mathrm{~mm} / \mathrm{s}$.

As can be seen in Figure 11 (right), some cracks appear on both sides of the tube. However, this is not the critical situation for stopping the test. The final point of the test is determined by the 
sudden increase of load due to the contact between the upper and lower internal faces of the tubes.
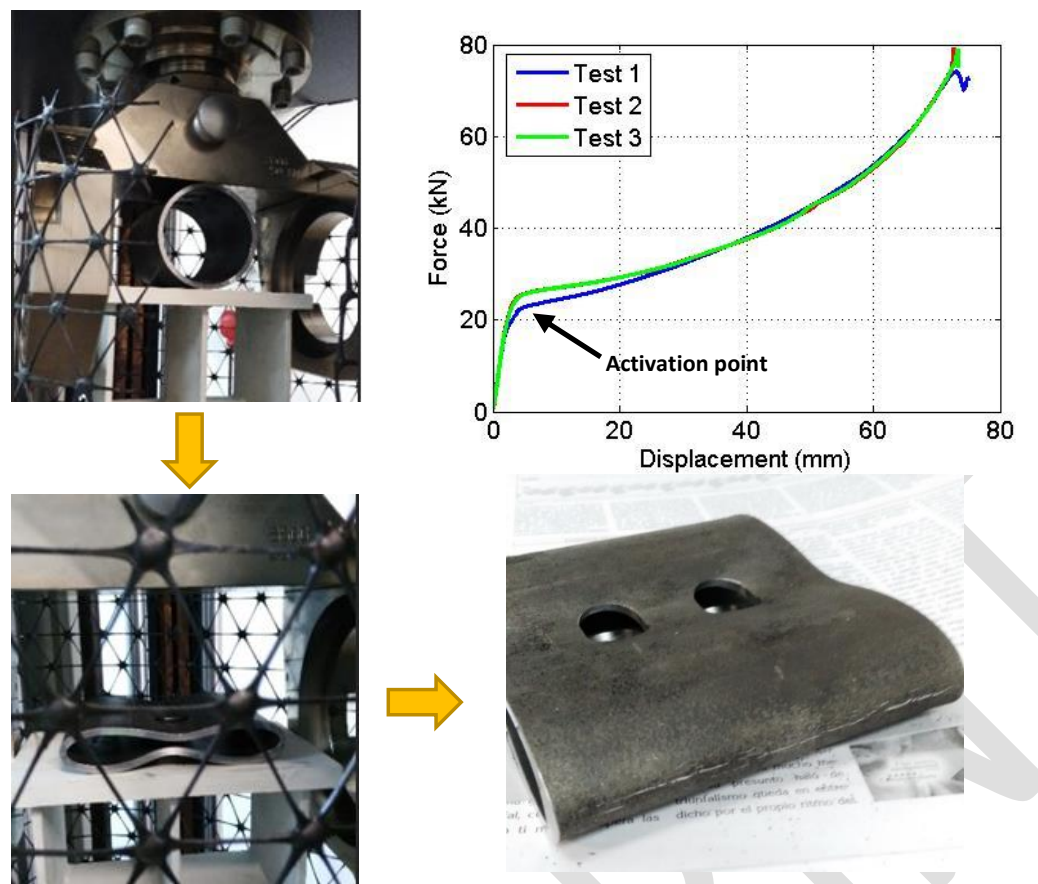

Figure 11. Performance of the quasi-static compression test on a tube and resultant force-displacement graph of the three samples tested.

Table 4. Activation force and absorbed energy of the tubes tested.

\begin{tabular}{|c|c|c|c|c|}
\hline Test & $\begin{array}{c}\emptyset_{\text {ext }} \\
(\mathrm{mm})\end{array}$ & $\begin{array}{c}\text { Thickness } \\
(\mathrm{mm})\end{array}$ & $\begin{array}{c}\text { Activation } \\
\text { force }(\mathrm{kN})\end{array}$ & $\begin{array}{c}\text { Energy } \\
(\mathrm{kJ})\end{array}$ \\
\hline 1 & 101,6 & 5 & 23 & 2,90 \\
\hline 2 & 101,6 & 5 & 26 & 2,48 \\
\hline 3 & 101,6 & 5 & 26 & 2,89 \\
\hline
\end{tabular}

\section{- Brakes}

A universal traction machine was used to carry out these tests. The compression of the tubes was measured using wire sensors in the same position as the ones in the dynamic test. The load is measured with the load cell of the machine, and a cable sensor was also included to corroborate the traction load of the assembly. The test speed was $2 \mathrm{~mm} / \mathrm{s}$ since this value is recommended by the EAD 340059-00-0106 [17], the document that suggests how the tests on rockfall barriers and their components should be performed.

In the Figure 12 the initial stage of the test is shown, as well as the final state of one brake, and the behaviour curves (load versus displacement) of the three brakes tested. 

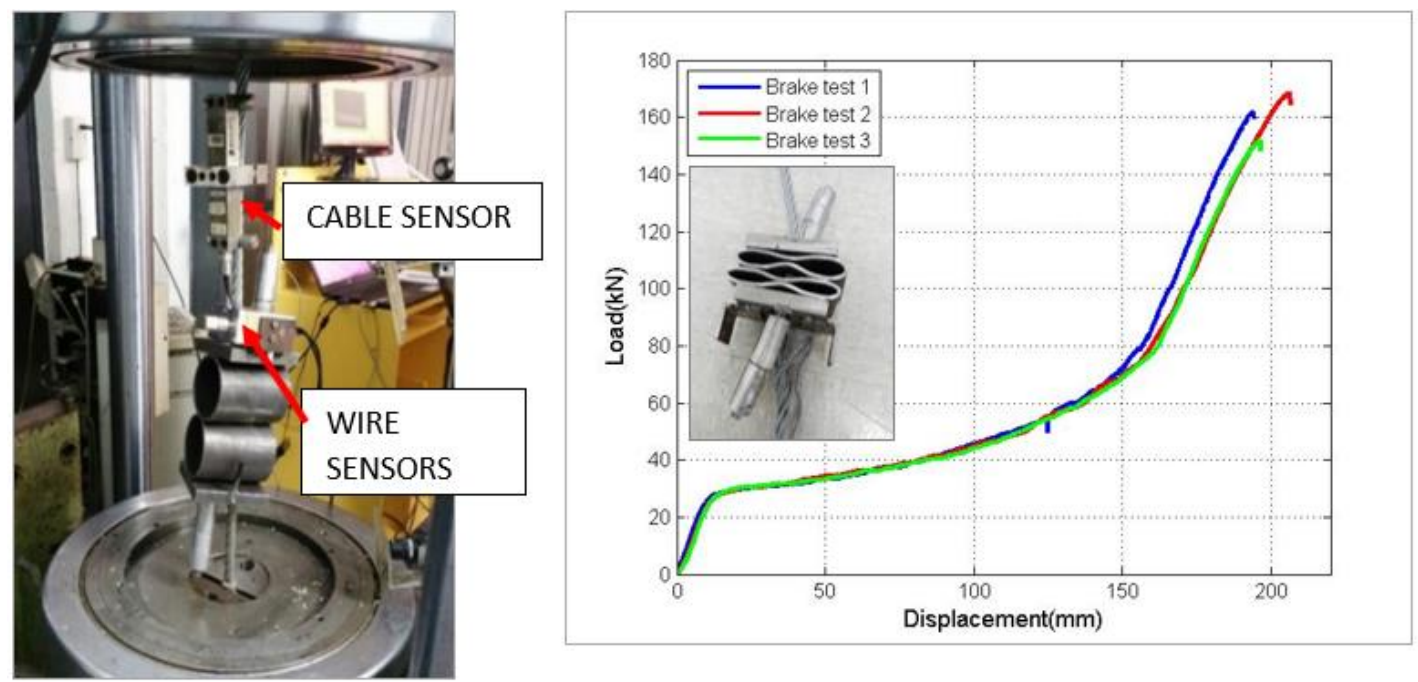

Figure 12. Performance of the quasi-static tension test on one brake and resultant force-displacement graph of the three samples tested.

Table 5. Activation force, ultimate force and absorbed energy of the complete brakes quasi-statically

tested.

\begin{tabular}{|c|c|c|c|}
\hline $\begin{array}{c}\text { Sample } \\
\text { No }\end{array}$ & $\begin{array}{c}\text { Activation } \\
\text { force }(\mathrm{kN})\end{array}$ & $\begin{array}{c}\text { Ultimate } \\
\text { force }(\mathrm{kN})\end{array}$ & $\begin{array}{c}\text { Energy } \\
(\mathrm{kJ})\end{array}$ \\
\hline 1 & 28 & 162 & 11,24 \\
\hline 2 & 28 & 170 & 12,64 \\
\hline 3 & 28 & 151 & 11,02 \\
\hline
\end{tabular}

All samples behaved identically in the first part of the test, and after that, the slope of sample 1 is slightly different from samples 2 and 3 due to the differences in the cables used as shown in Figure 12.

Figure 13 shows the compression length of the tubes obtained using two wire sensors and the extension length of the complete barrier in the same graph. An inflexion point from which the tubes stop compressing can be observed. From that moment, the brake extension is mainly due to two facts. The first one is the deformation of the cables until breakage. Knowing that the sum of the two pieces of cable make a total length of $1100 \mathrm{~mm}$, the rope is able to extend up to 50 $\mathrm{mm}$ getting an ultimate load value of $200 \mathrm{MPa}$. However, the maximum load for the complete brake is $160.2 \mathrm{kN}$, so the maximum elongation of a $1100 \mathrm{~mm}$ brake is $26 \mathrm{~mm}$. Hence, the divergence of the two curves in Figure 13 is not only due to the extension of the cables, but there is another fact that makes the brake extend more, that is the rotation of the set plugs+tubes due to the eccentricity, movement that progressively appears and gets more pronounced at the end of the test (Figure 14). This movement adds an additional length of the extension of the brake of $25 \mathrm{~mm}$. 


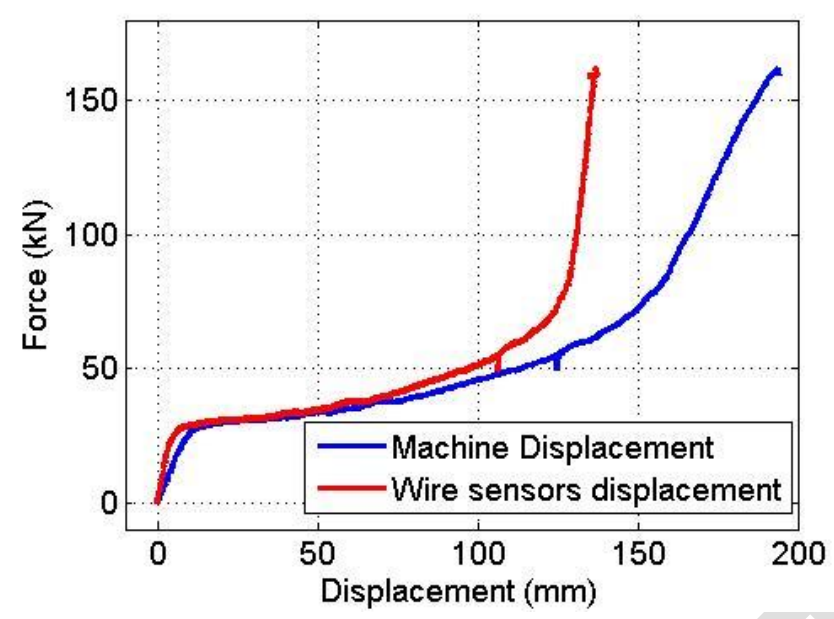

Figure 13. Force-displacement graph, comparing the curves obtained through the extension of the brake measured by the machine cross-head displacement sensor (in blue) and the displacement measured by the wire sensors (in red).
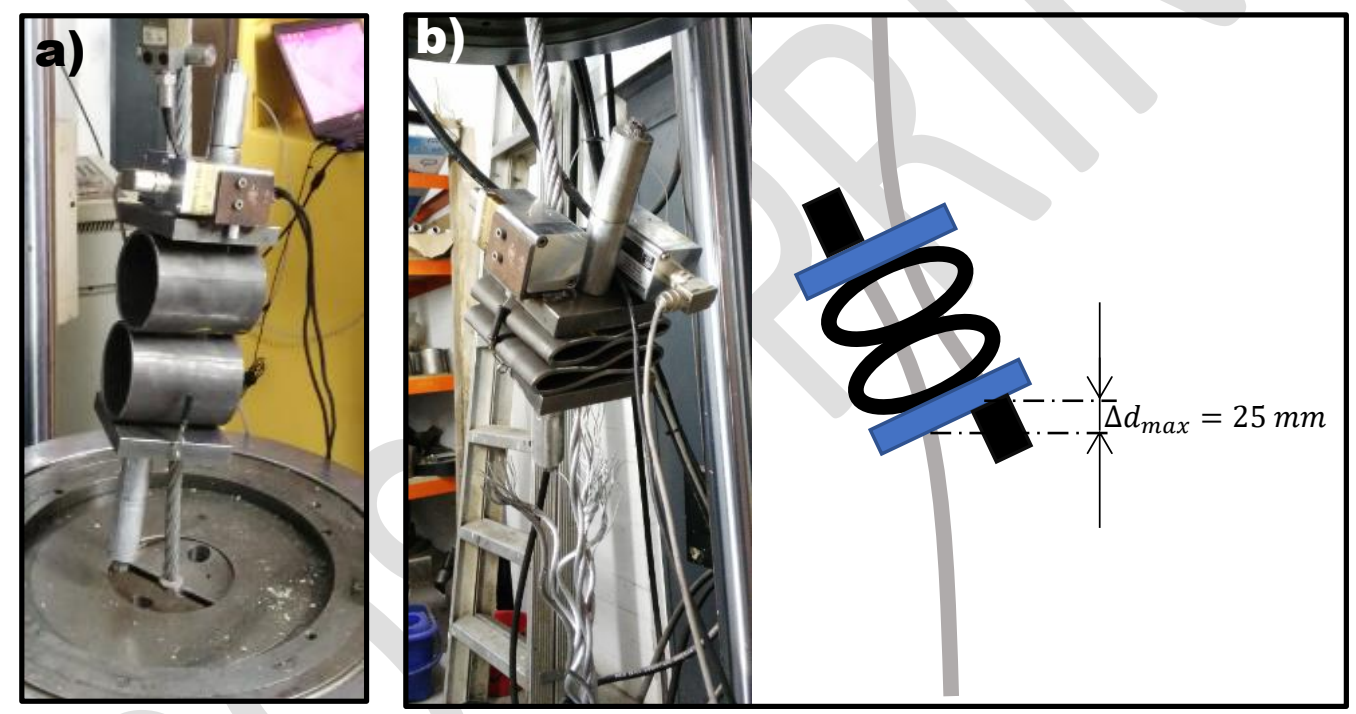

Figure 14. Displacement due to eccentricity a) at the beginning of the test, and b) at the final stage of the quasi-static test.

\subsection{Quasi-static test vs. Dynamic test}

With the aim of analysing the analogies and differences between quasi-static and dynamic tests on the same brake, load-displacement curves are represented together in Figure 15. The displacement in the $x$ axis comes from the wire sensors, so it is directly related to the behaviour of the tubes. 


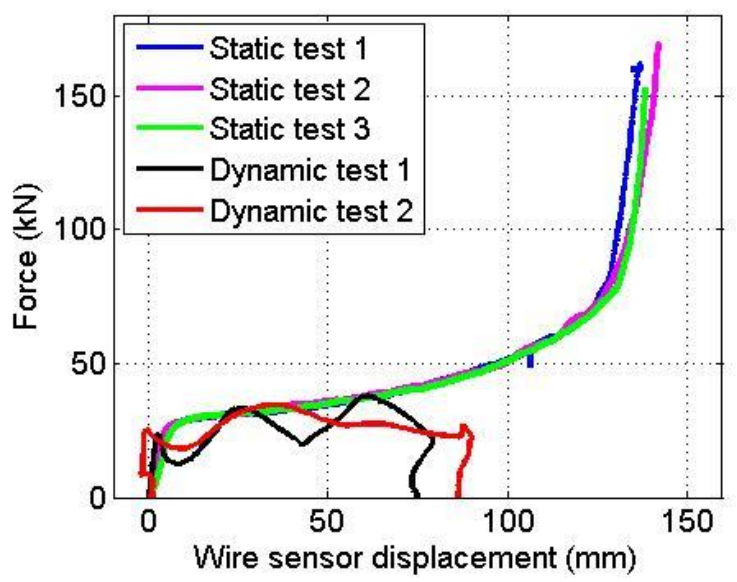

Figure 15. Graph of load vs displacement measured by the wire sensors of Brake 1 ( 2 tubes, $\phi_{\text {ext }} 101.6$ $\mathrm{mm}, \mathrm{e}=5 \mathrm{~mm})$. Comparison between quasi-static and dynamic results.

The activation force in both test types is similar.

The quasi-static test curves are more uniform than those in the dynamic tests. The latter have a wavy shape due to the load application method, which is not constantly growing but comes from the reaction of the drop of a mass linked to the brake cable, causing impact, rebounds and partial energy recovery, which does not happen in quasi-static conditions. Although all these situations are relatively uncontrollable and can disturb the curve, the activation force is similar both in quasi-static and in dynamic tests, demonstrating the repetitive behaviour of the brakes not only in quasi-static tests, but also in the dynamic ones.

When the force level is compared in the two tests, it can be noted that the quasi-static tests determine the maximum force level for each displacement point, since the dynamic graphs are always under the quasi-static curves in all cases. The maximum force level of the dynamic tests reaches static force levels at most (see force levels at $25 \mathrm{~mm}$ and $60 \mathrm{~mm}$ in dynamic test 1 and $35 \mathrm{~mm}$ in dynamic test 2).

\subsection{Observations from experimental tests}

\section{* Observation 1}

The quasi-static test of the brakes with tubes of $101.6 \mathrm{~mm}$ and $5 \mathrm{~mm}$ of thickness does not display optimal performance. The brake activates at low load $(28 \mathrm{kN})$, the tube deformation is very quickly completed (at a force of $75 \mathrm{kN}$ ) and the increase in length of the brake in the last part is mainly caused by the cable deformation until breakage $(160 \mathrm{kN})$.

An option to improve the efficiency of the brake is to make the curved zone disappear where only the cable extension acts. The increase of the thickness of the tubes is considered to provide a higher activation force and a longer tube compression process.

The search for a brake that dissipates more energy will be performed numerically in the next sections. The procedure is the following: first, the brake model is calibrated using the results of the experimental tests. Then, some parameters are varied in the geometry, to find the solution that behaves best and absorbs most energy. 


\section{* Observation 2}

Cables tested independently in quasi-static conditions break at a load of 190-200 kN. However, quasi-static tests on brakes show that the ultimate load is lower, around $160 \mathrm{kN}$. The reason for this premature break is the asymmetry of the brake. During compression, the plugs and tubes tend to adopt a certain angle instead of remaining horizontal. This angle makes the edges of the plug slide against the cables and accelerates the breaking of the cables due to the cut of some of their wires.

\section{* Observation 3}

Although, in the tests carried out on independent tubes cracks appear on both sides of the samples, this does not happen in the tests on the full brake. In tests on brakes, the cables start to plastically deform until breakage before the cracking of the tubes.

\section{Calibration of the numerical model}

\section{* Cables}

A numerical implementation of the cable, including all the wires of the cable was discarded due to the geometric complexity and large amount of contacts to include, which could cause an extremely large computational time. As an alternative, an equivalent simplified model is implemented, with a slender cylindrical shape of $16 \mathrm{~mm}$ diameter. To verify the cable model, a quasi-static test is reproduced, so a cable of $680 \mathrm{~mm}$ length is fixed at one end and a displacement with a constant increment is induced at the other end. A multilinear elasto-plastic material category is assigned to the model. The curve definition is done by using the experimental results of the cable. The stress is calculated by dividing the load at each point by the equivalent area of the cable $\left(A_{e q}=\frac{\pi \phi^{2}}{4}\right.$ where $\left.\phi=16 \mathrm{~mm}\right)$. Moreover, explicit calculation requires "true" stress-strain data, calculated by using expressions (1) and (2)

$$
\begin{aligned}
& \sigma_{\text {true }}=\sigma(1+\varepsilon) \\
& \varepsilon_{\text {true }}=\ln (1+\varepsilon)
\end{aligned}
$$

At the end of the curve, an additional point had to be added, with coordinates ( $\varepsilon_{\text {plastic true }}, \sigma_{\text {true }}$ ) $=(0.2346,1213)$. This was due to the fact that in the future models of the brake, the cable, besides a traction force, also is going to suffer bending in some points, especially in the contact zone between the cable and the plug, due to the eccentricity shown in Figure 14 . If this additional point is not included, the cable prematurely breaks on the bending areas, since the modelization of the cable is done by using solid elements and not truss elements without any bending stress.

The material data, cable model and results are shown in Figure 16. A good fit between the experimental and numerical model is accomplished, which enables the use of the simplified model in the complete brake model. 

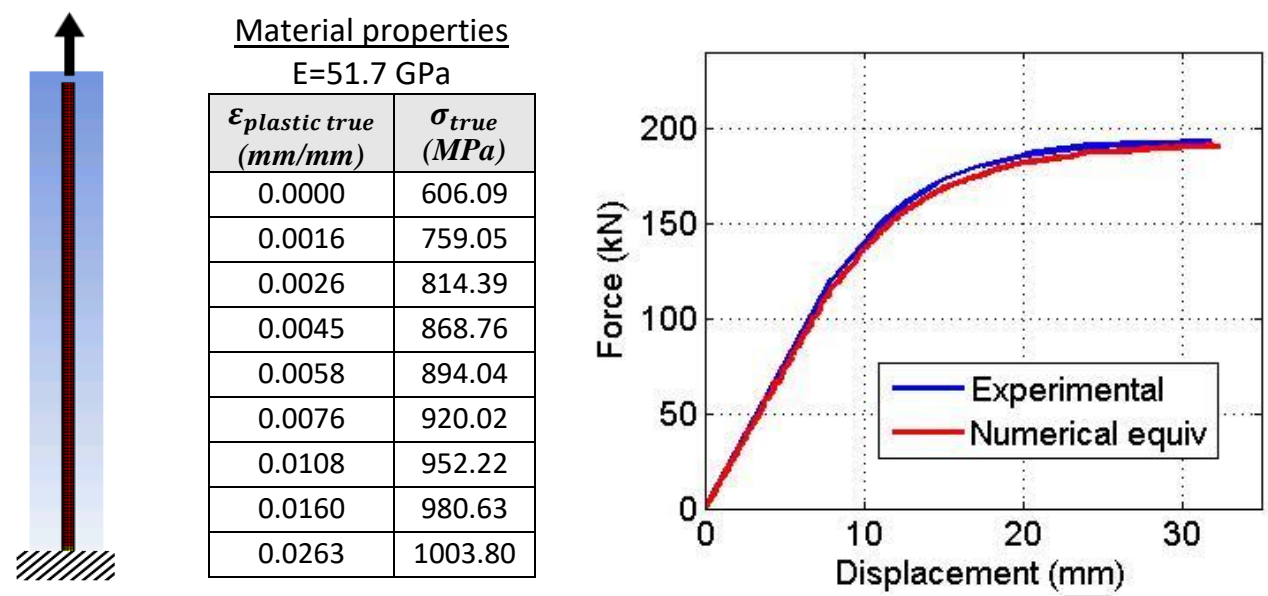

Figure 16. FEM model of the cable and boundary conditions (left), material properties of the model (centre) and force-displacement graph comparing FEM and quasi-static test (right).

\section{* Tubes}

The material category for tubes also has multilinear elasto-plastic behaviour. The Young Modulus of the steel is $210 \mathrm{GPa}$ and the plastic part of the curve is implemented as a line from the yield stress-strain (360 MPa) to the ultimate stress-plastic strain (744 MPa- 19.53\%).

A first calculation was performed with a hexahedral mesh, with 2 elements over thickness and reduced integration, since this configuration provides a big computational time-saving $(61.3 \%$ with respect to the final model without hourglassing problems). However, due to the great deformation of the tube, in the final part of the test the hourglassing phenomena appears. Several options were tried to make the hourglassing disappear. The first option, to increase the number of elements in the thickness was discarded, since a small element increment (to 4 elements) maintains the hourglassing phenomena in the model, and higher values lead to an extremely high computational cost (more than a week). The same occurred with a change to a complete integration. The solution adopted that provided a solution without errors in a reasonably low working time (16.6 hours) was the use of tetrahedral elements.

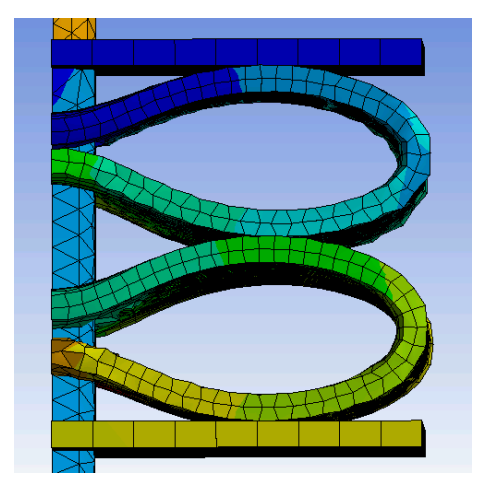

Figure 17. Hourglassing problems arise with the meshing method chosen initially. 
The suitability of the model of the tubes was corroborated by carrying out a simulation of compression of two tubes. The result was compared with the behavior curve extracted from the wire sensor on the complete barrier (red curve on Figure 13), and a very good fitting was found, as can be seen in Figure 18.

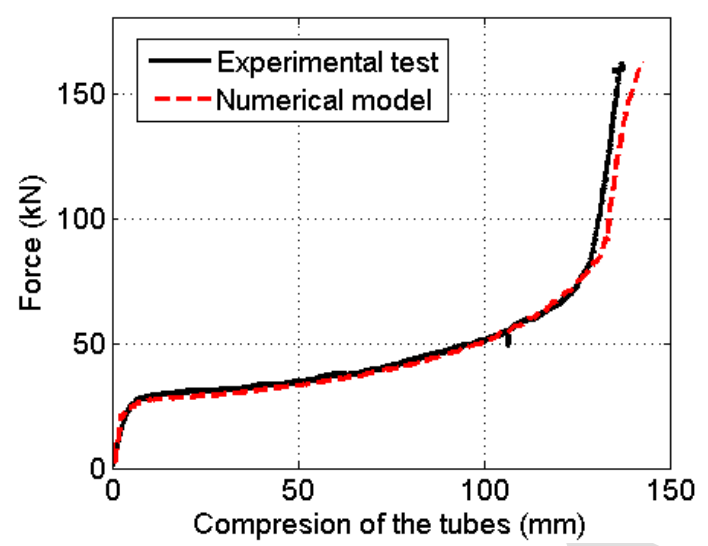

Figure 18. Graph of Force versus compression of the tubes. Comparison between the experimental test measured by the wire sensors and the numerical model.

Plugs

Two alternatives were studied. The first option consisted on giving the plugs the real material behavior: that is bilinear elastoplastic with a young modulus of $235 \mathrm{MPa}$, an ultimate stregth of $360 \mathrm{MPa}$ and elongation at brake of $23 \%$. The second option was to simplify these square pieces using rigid elements.

\section{* Complete brake}

Two models were performed with the same cable and tubes characteristics, and with the only diference on the material on the plugs. The model with elastoplastic plugs had a computational time of 4.94 days, whilst the model with rigid plugs took 16.6 hours. The numerical models were compared to the experimental test (Figure 19). It was found that both load-displacement curves were very similar. 


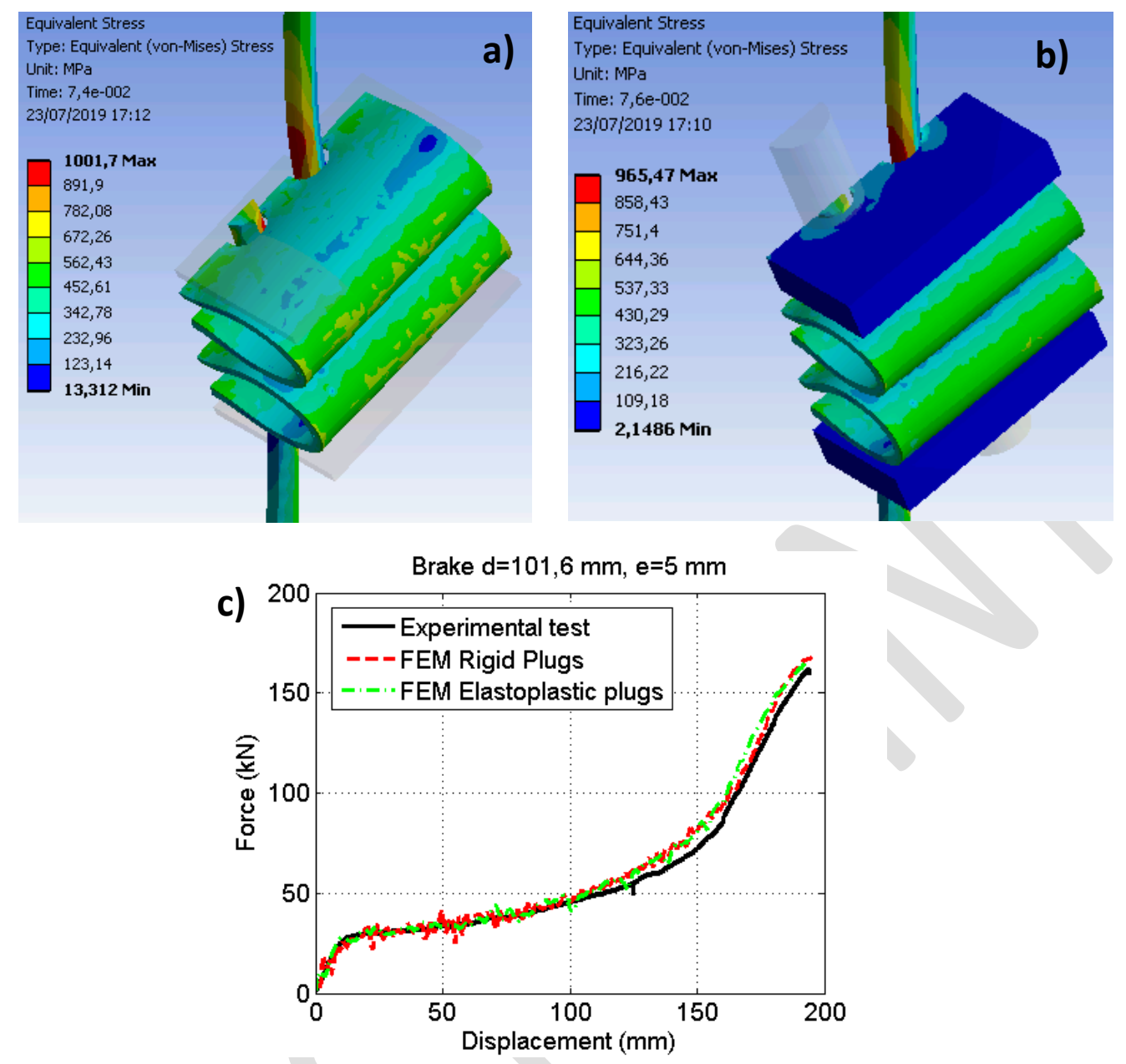

Figure 19. Results of FEM model of the brake a) with rigid plugs, b) with elastoplastic plugs, and c) comparative graph force-displacement between FEM models and quasi-static test.

\subsection{Analysis of the energy absorbed by the brake through the numerical simulation}

The total energy that the brake can absorb is divided into the following components:

* The plastic deformation of the tubes

* The plastic deformation of the cables

* The plastic deformation of the plugs (Figure 20).

* The friction among cables and the hole edges of the plugs. 


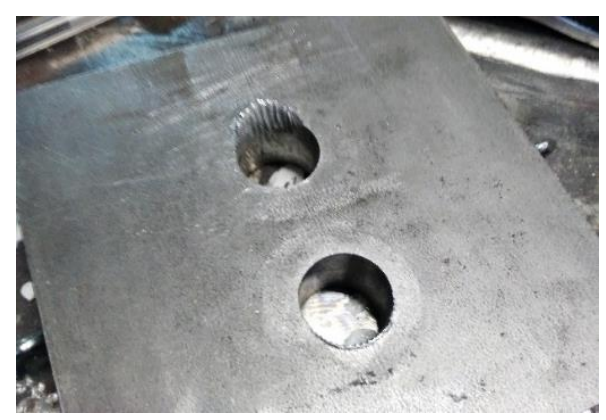

Figure 20. Deformation on one edge of a plug due to the friction between it and the cable passing through it.

This analysis was done using the numerical model of the brake using elastoplastic plugs, which is the more realistic model in terms of energy distribution, so it can give closer results to the real brake than the one with rigid plugs. The distribution of energy given by the software Ansys can be seen in Figure 21 as well as the integration of the complete load-displacement curve given on Figure 19 which is the total energy absorbed by the brake.

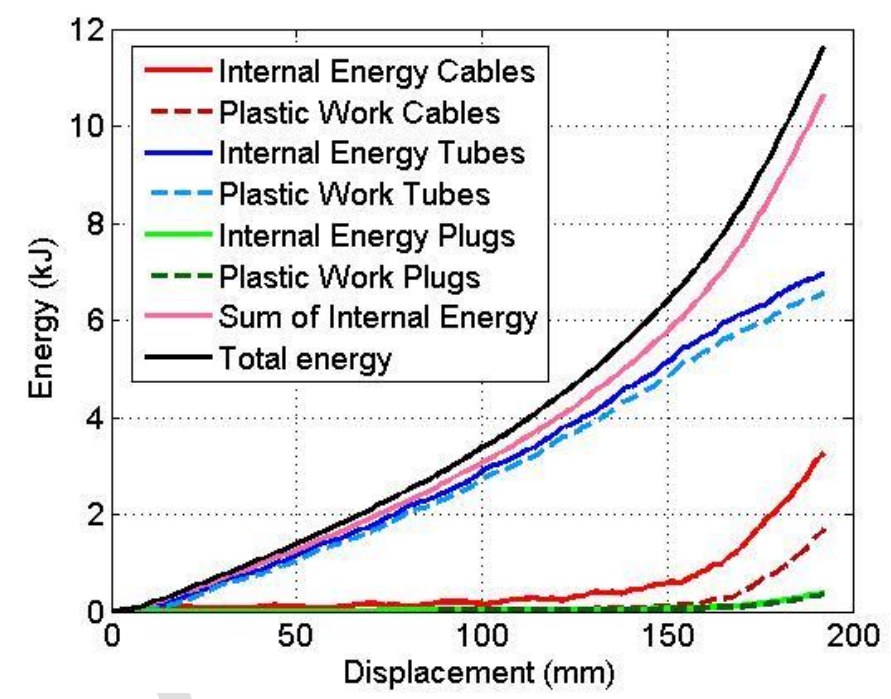

Figure 21. Graph of energy vs elongation of the brake.

The main dissipation mechanism at the beginning of the test is the compression of the tubes. Reaching $80 \%$ of the compression capacity, the energy absorption of the tubes starts to decrease its slope and the energy due to the elastoplastic deformation of the cables becomes more relevant, reaching $30 \%$ of the total internal energy. The influence of the internal energy of the plugs is $3.8 \%$ of the internal energy of the full model.

The software also gives values of contact energy during the solving process, with a final value of $7.2 \mathrm{~kJ}$. It must be considered that the energy given in Figure 22 only gives half of the energy due to the symmetry on the model.

The contact energy should be attributed to two different mechanisms:

- The contact between the tubes and the plugs, which allows the compression of the tubes. Thus, the contact energy due to this should be the same as the energy of deformation (the internal energy) of the tubes, which makes a total of $6.96 \mathrm{~kJ}$. 
- The contact between the cables and the hole edges of the plugs. The value of this energy would be the difference between the total contact energy, and the one of the previous point; that is, $0.2 \mathrm{~kJ}$. Thus, the friction due to this mechanism does not play an important role unlike the expected at the beginning of the section.

The difference between the sum of internal energies of each component and the total energy coming from the integration of the Force-displacement curve is attributed to the increase of extension of the brake due to its asymmetry, explained in section 4.2 and Figure 13.

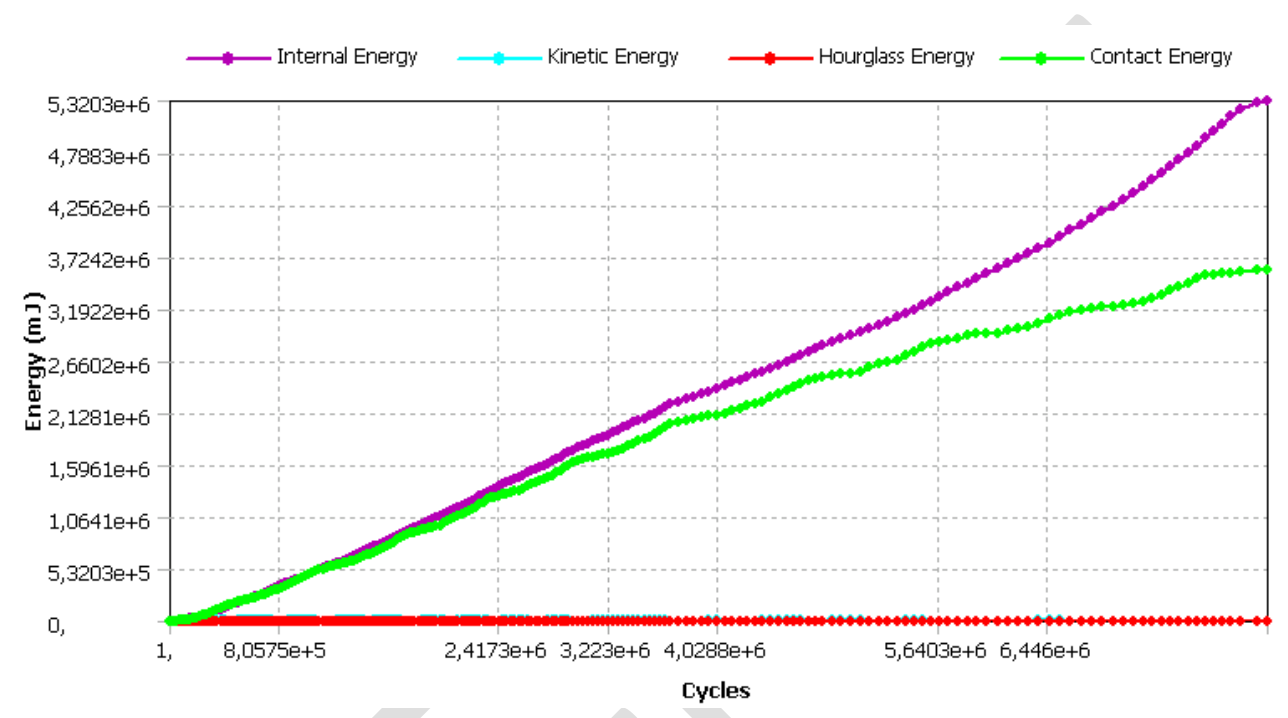

Figure 22. Graph of the energy summary in every solving cycle given by Ansys.

\section{Improvement in the geometry}

The FEM model and experimental test of the calibrated brake gave a low value of the energy absorbed, as explained in observation 1. To get a rise of this value and make the brake competitive among others already in the market the use of tubes with higher thickness is proposed which implies a raise on the volume of material that is plastically deforming. The numerical model used for this study was the one with rigid plugs, as it presents a similar ForceDisplacement curve from the model with elastoplastic plugs, but with a reduction of $86.6 \%$ on the computational cost. With the calibrated model with rigid plugs, three models are calculated with different diameters and thicknesses of tubes. Dimensions of each model are specified in Table 6. A supplier's catalogue of S355 J2 (ST52) steel tubes was used to select the dimensions.

Table 6. Dimensions of the tubes of the different FEM models

\begin{tabular}{|c|c|c|}
\hline $\begin{array}{c}\text { Model } \\
\mathrm{n} \text { o }\end{array}$ & $\begin{array}{c}\text { Diameter } \\
(\mathrm{mm})\end{array}$ & $\begin{array}{c}\text { Thickness } \\
(\mathrm{mm})\end{array}$ \\
\hline 1 (ref) & 101.6 & 5 \\
\hline 2 & 114.3 & 6.3 \\
\hline 3 & 133 & 8 \\
\hline 4 & 133 & 10 \\
\hline
\end{tabular}


The simulated models are shown in Figure 23. The highest activation force is reached with model 4 , followed by model 3 . These two models are also the best in terms of energy absorption (Table 7). Although material optimization is pursued, in terms of energy per unit of mass of the tubes, the optimal results are reached in low-dimension brakes (models 1 and 2), which also have a low energy dissipation in absolute terms. Since the optimal brakes have, in the best cases, an energy dissipation capacity $26 \%$ lower than the brakes with $133 \mathrm{~mm}$ diameter, models 3 and 4 are preferred. Therefore, experimental tests on models 3 and 4 are performed to corroborate the numerical models and to find out the exact value of their maximum load, since, as observed in section 4.4, it is not coincident with the maximum load of the independent cable. However, it is not known whether there is a dependency of this maximum value on the tube dimensions.
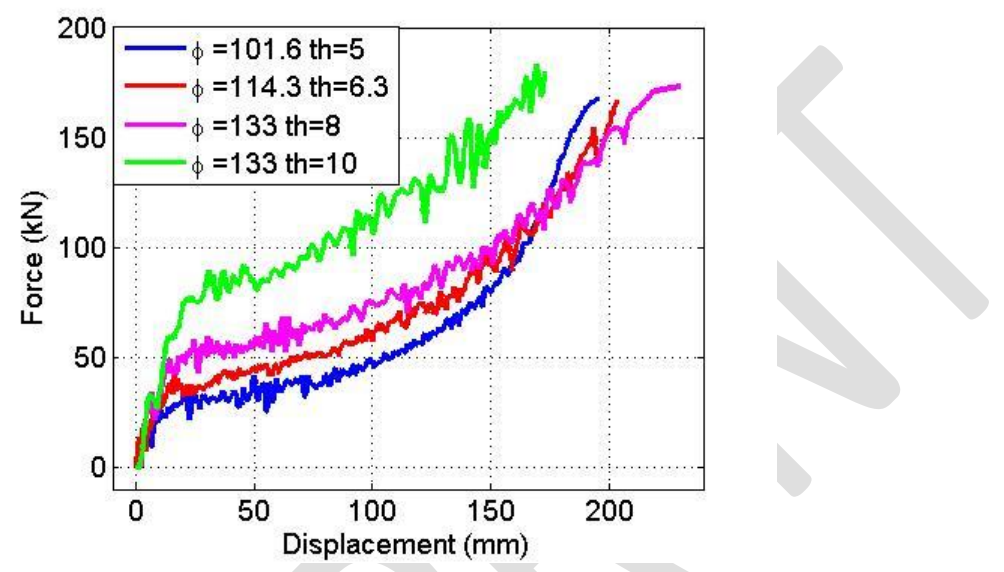

Figure 23. Force-Displacement graph of the 4 brakes simulated. The values of diameter and thickness are expressed in $\mathrm{mm}$.

Table 7. Mass and energy absorbed by the FEM models.

\begin{tabular}{|c|c|c|c|c|c|}
\hline & Dimensions & $\begin{array}{c}\text { Energy } \\
2 \text { tubes } \\
(\mathrm{kJ})\end{array}$ & $\begin{array}{c}\text { Mass/1 } \\
\text { meter } \\
\text { of tube } \\
(\mathrm{kg} / \mathrm{m})\end{array}$ & $\begin{array}{c}\text { Mass } \\
2 \\
\text { tubes } \\
(\mathrm{kg})\end{array}$ & $\begin{array}{c}\text { Energy/Mass } \\
(\mathrm{kJ} / \mathrm{kg})\end{array}$ \\
\hline $\begin{array}{c}\text { Brake } \\
\text { model 1 }\end{array}$ & $\begin{array}{c}d=101.6 \mathrm{~mm} \\
e=5 \mathrm{~mm}\end{array}$ & 11.8 & 12.2 & 2.928 & 4.03 \\
\hline $\begin{array}{c}\text { Brake } \\
\text { model 2 }\end{array}$ & $\begin{array}{c}d=114.3 \mathrm{~mm} \\
e=6.3 \mathrm{~mm}\end{array}$ & 14.6 & 17.2 & 4.128 & 3.53 \\
\hline $\begin{array}{c}\text { Brake } \\
\text { model 3 }\end{array}$ & $\begin{array}{c}d=133 \mathrm{~mm} \\
e=8 \mathrm{~mm}\end{array}$ & 19.8 & 25.2 & 6.048 & 3.27 \\
\hline $\begin{array}{c}\text { Brake } \\
\text { model 4 }\end{array}$ & $\begin{array}{c}d=133 \mathrm{~mm} \\
e=10 \mathrm{~mm}\end{array}$ & 19.6 & 30.9 & 7.416 & 2.64 \\
\hline
\end{tabular}

The results of the quasi-static tests on brakes 3 and 4 , together with the numerical models generated before, can be seen in Figure 24. The numerical models are able to reliably reproduce the real behaviour of the brakes in both cases. The ultimate brake load is in the same range in the two brake types, around 170 and $175 \mathrm{kN}$. The energy absorbed, calculated as the area under the load-displacement curve, is also practically the same in the two cases, with values of 20 and $21 \mathrm{~kJ}$ in the case of the $8 \mathrm{~mm}$ thickness, and 21 and $22 \mathrm{~kJ}$ in the case of $10 \mathrm{~mm}$ thickness. With these results, another parameter is needed to decide which is the best option, so the efficiency by unit of mass is used. Considering the mass of the tubes (Table 7), efficiencies of 3.5 and 2.83 $\mathrm{kJ} / \mathrm{kg}$ are obtained. Additionally, it can be noted that the brakes with greatest thickness are not 
able to completely compress, because the breakage of the cables occurs first (Figure 25). In conclusion, the most suitable brake among those analysed in this work is Model 3 , with a diameter of $133 \mathrm{~mm}$ and a tube thickness of $8 \mathrm{~mm}$.

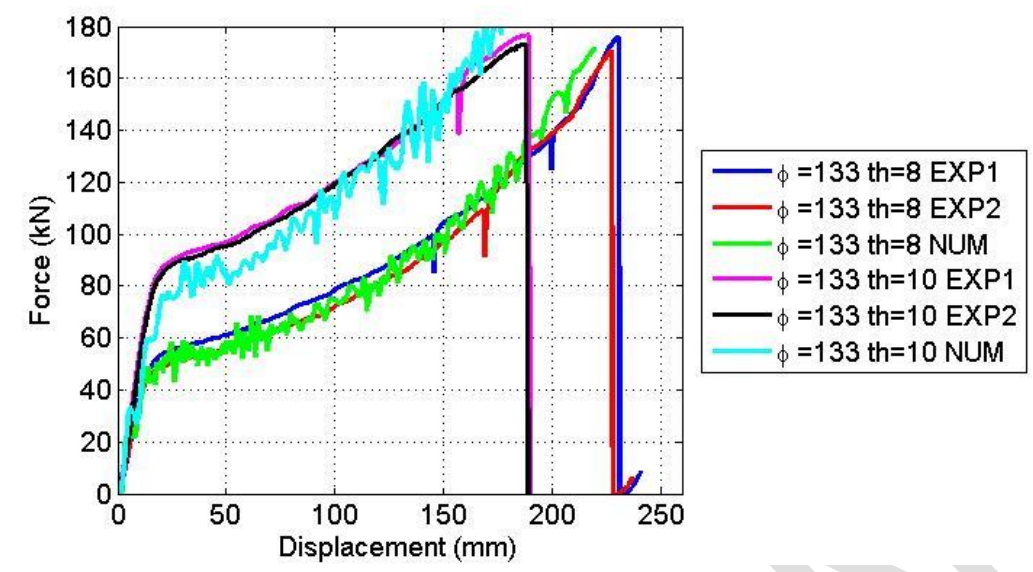

Figure 24. Force-Displacement graph of the quasi-static tests and numerical simulations of brake models 3 and 4.
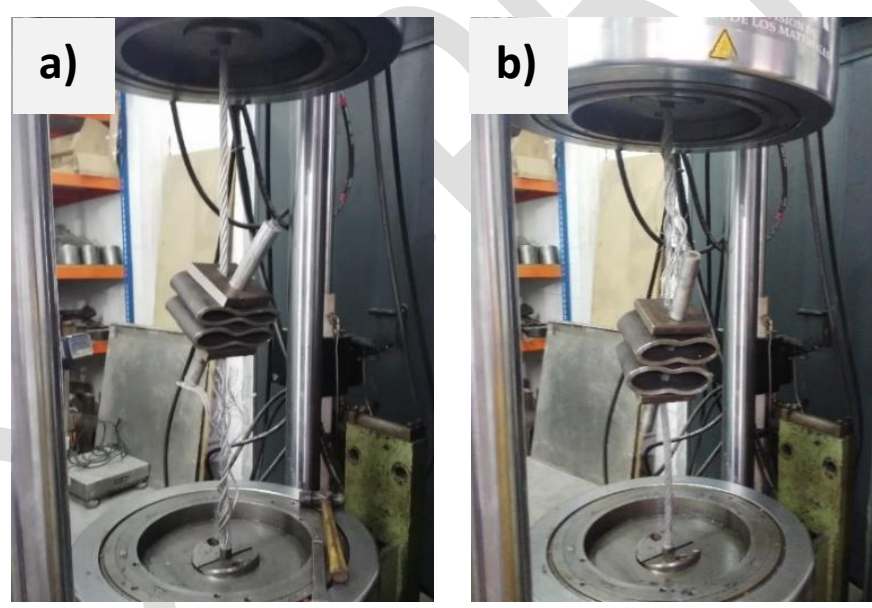

Figure 25. Final state of the brakes after the quasi-static tests: a) Brake model $3(\phi 133 \mathrm{~mm}, \mathrm{th}=8 \mathrm{~mm})$ and b) Brake model $4(\phi 133 \mathrm{~mm}$, th=10 mm).

Once the geometry of the tubes is decided, an increment on its number is convenient to further increase the absorbed energy. Since the brakes should be manoeuvrable (in terms of dimensions and weight) for the operators that install them, some limitations on the length and size of the tubes were considered. The length was limited to $800 \mathrm{~mm}$ and the diameter of the tubes had a maximum diameter of $133 \mathrm{~mm}$. With these limitations, brakes with 6 tubes can be used, absorbing $55 \mathrm{~kJ}$. 


\section{Behaviour of the selected brake in a complete barrier}

The new design of brake was numerically tested in a complete barrier to corroborate its validity. The barrier geometry selected is the IBT-150, whose experimental tests and numerical modelling were described in [2]. It has modules of $10 \mathrm{~m}$ length and $3 \mathrm{~m}$ high, erected by means of hinged pipe posts which are kept in position with one upstream cable per post. At each side and upstream cable, there is a brake. The software used for the modelling of the barrier is Abaqus, and the solver type is explicit due to the high-speed motion and presence of non-linearities in the model [23]. All the numerical features and the material properties of the model were maintained the same as in [2] and the only changes were carried out in the force-displacement law of the brake, which is defined as an axial connector. It was decided to install a brake with six tubes, as it can dissipate up to $55 \mathrm{~kJ}$. The force-displacement curve of the brake with 2 tubes was extrapolated to the case of a brake of 6 tubes as shown in Figure 26. The reason for taking a value of 6 tubes is related with the limitations taken to allow manoeuvrability, as explained in the last section.

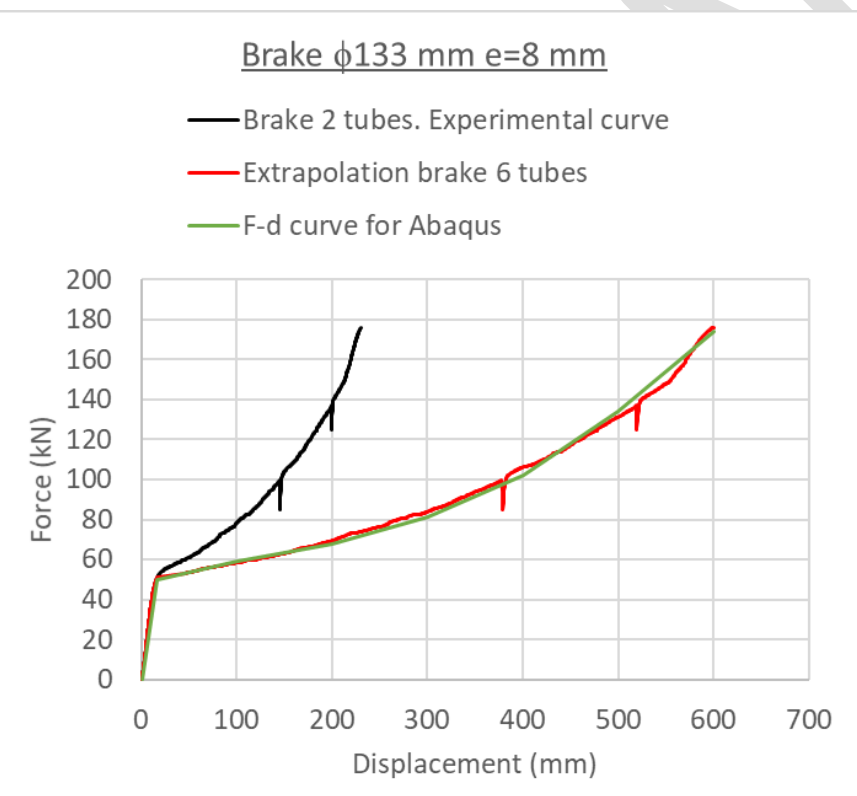

Figure 26. Extrapolation of the force-displacement law of a 2-tube brake to the case of a 6-tube brake.

The block has a polyhedral shape as described in EAD 340059-00-0106 [17]. To find the maximal energy, an iterative procedure was performed, in which the initial speed of the block was increased until the barrier is not able to stop the block, due either to the breakage of the membrane or the breakage of the perimeter cables that keep the membrane in place.

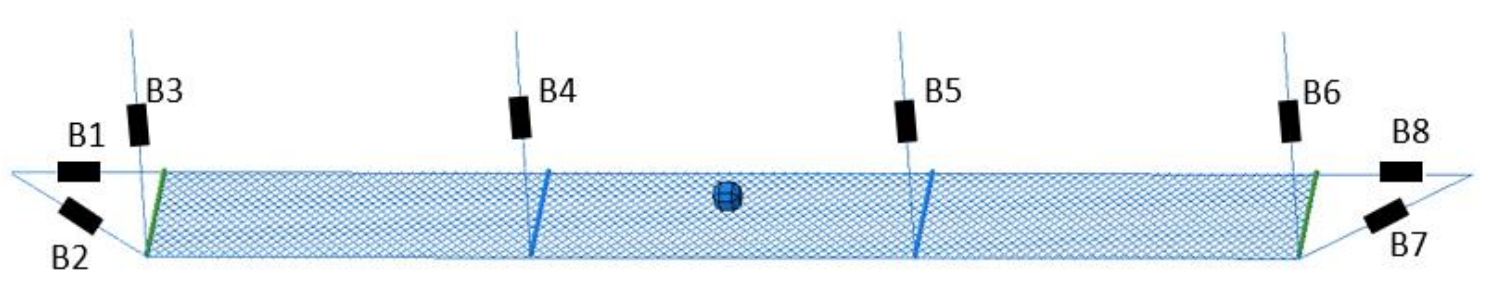

Figure 27. Location of the brakes 
The barrier with 6-tube brakes (Figure 27) was compared with a barrier without any brakes in it. While the barrier without brakes can resist an impact of $172 \mathrm{~kJ}$, the model with 6-tube brakes in all the side and upstream cables was able to resist $277 \mathrm{~kJ}$, which means an increase of $61 \%$ in the energy absorbed by the complete structure. This percentage could be increased or reduced depending on the number of tubes included in the brake. The critical point that makes the barrier fail the test is the breakage of the perimeter cable that is closest to the post bases (Figure 28).

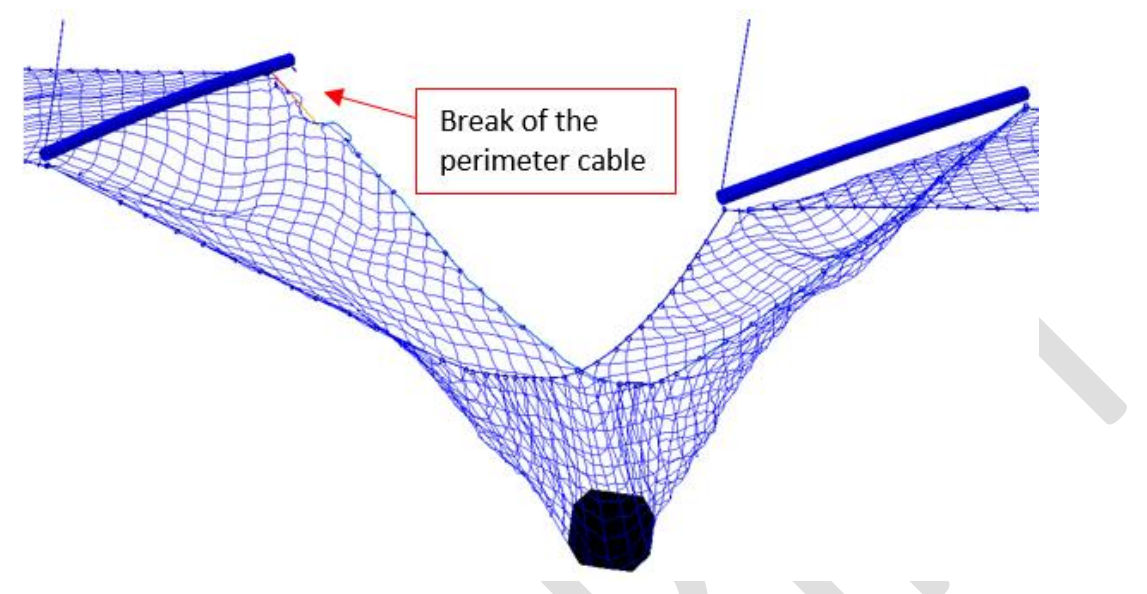

Figure 28. Breaking point of the barrier IBT-150 with 6-tube brakes.

The total elongation of the brakes was extracted from the simulation, as well as the force next to each one, to find out the energy absorbed, calculated by the integration of the forcedisplacement curve of each brake. The results can be seen in Table 8 .

Table 8. Dimensions of the tubes of the different FEM models

\begin{tabular}{|l|c|c|c|}
\hline \multicolumn{1}{|c|}{ Brake position } & $\begin{array}{c}\text { Elongation } \\
\mathbf{( m m )}\end{array}$ & $\begin{array}{c}\text { Total Energy } \\
\mathbf{( k J )} \\
\text { Elastic+plastic } \\
\text { deformation }\end{array}$ & $\begin{array}{c}\text { Energy due to } \\
\text { plastic } \\
\text { deformation } \\
(\mathbf{k J})\end{array}$ \\
\hline B1. Lateral cable. Back Left & 419.3 & 29.51 & 26.87 \\
\hline B2. Lateral cable. Front Left & 359.8 & 25.05 & 21.42 \\
\hline B3. Upstream cable. Extreme left & 14.3 & 0.8 & 0 \\
\hline B4. Upstream cable. Central left & 239.8 & 11.72 & 10.26 \\
\hline B5. Upstream cable. Central right & 224.02 & 11.84 & 10.22 \\
\hline B6. Upstream cable. Extreme right & 10 & 0.75 & 0 \\
\hline B7. Lateral cable. Front right & 361.1 & 24.41 & 20.51 \\
\hline B8. Lateral cable. Back right & 425.5 & 31.02 & 28.57 \\
\hline \multicolumn{1}{|c|}{ Total } & & $\mathbf{1 3 5 . 1}$ & $\mathbf{1 1 7 . 8 5}$ \\
\hline
\end{tabular}

The sum of the energies absorbed by all the brakes is $154.29 \mathrm{~kJ}$, a higher value than the increase in energy absorbed (of $105 \mathrm{~kJ}$ ) in comparison with the barrier without brakes. This could be because part of energy applied in the impact of the block is converted into energy absorbed by plastic deformation of the elements of the barrier, and this plastic deformation is allocated in a different way than in the barrier without brakes. To investigate this, the plastic energy dissipated by each component in both models was extracted (Table 9). The energy dissipated by the 
perimeter and lateral cables was divided between those closest to the slope, named "INT" and those furthest from the slope, named "EXT".

Table 9. Plastic energy absorbed by the different components of the barrier in the IBT-150 model with and without brakes.

\begin{tabular}{|c|c|c|c|c|}
\hline \multirow{2}{*}{} & \multicolumn{2}{|c|}{ Model WITHOUT brakes } & \multicolumn{2}{c|}{ Model WITH brakes } \\
\cline { 2 - 5 } & $\begin{array}{c}\text { Plastic energy } \\
\text { absorbed (kJ) }\end{array}$ & $\begin{array}{c}\text { \% of total } \\
\text { plastic } \\
\text { energy }\end{array}$ & $\begin{array}{c}\text { Plastic energy } \\
\text { absorbed (kJ) }\end{array}$ & $\begin{array}{c}\% \text { of total } \\
\text { plastic } \\
\text { energy }\end{array}$ \\
\hline Net & 0.18 & $0.57 \%$ & 8.36 & $5.98 \%$ \\
\hline $\begin{array}{c}\text { Perimeter } \\
\text { and lateral } \\
\text { cables (INT) }\end{array}$ & 17.6 & $55.43 \%$ & 5.63 & $4.02 \%$ \\
\hline $\begin{array}{c}\text { Perimeter } \\
\text { and lateral } \\
\text { cables (EXT) }\end{array}$ & 11.77 & $37.07 \%$ & 2.66 & $1.90 \%$ \\
\hline $\begin{array}{c}\text { Upstream } \\
\text { cables }\end{array}$ & 0 & $0 \%$ & 0 & $0 \%$ \\
\hline Posts & 2.20 & $6.93 \%$ & 5.14 & $3.68 \%$ \\
\hline Brakes & - & - & 117.85 & $84.39 \%$ \\
\hline SUM & $\mathbf{3 1 . 7 5}$ & $\mathbf{1 0 0 \%}$ & 139.64 & $100 \%$ \\
\hline
\end{tabular}

In the model without brakes the highest percentage of energy (92.5\%) is absorbed by the perimeter and lateral cables, with a total of $29.37 \mathrm{~kJ}$. However, with the addition of the new brakes, these structural components only contribute $8.29 \mathrm{~kJ}$, which means $5.92 \%$ of the total plastic energy that the whole model can absorb. The only point in common is that, in both cases, the perimeter and lateral cables closest to the slope absorb more energy than the ones further from there. In contrast to the perimeter and lateral cables, the net and the posts absorb greater amounts of plastic energy in the model with brakes than in the one without any brake. The reason could be the following: the inclusion of brakes leads to greater sliding of the complete net towards the impact point, but the interconnection between the perimeter cables and the net limits this movement (Figure 29). Both ends of the posts are pulled towards the impacted module. The end of the posts fixed to the ground cannot move, but the force on the free ends causes their bending and plastic deformation. At the same time, on the net, there is a new pattern of stress, which implies greater deformation than in the model without brakes. The central cross pattern is not the only location of main stresses, but additional cross shapes appear on both sides, starting from the net behind the post ends and connecting to the main cross in the centre. 


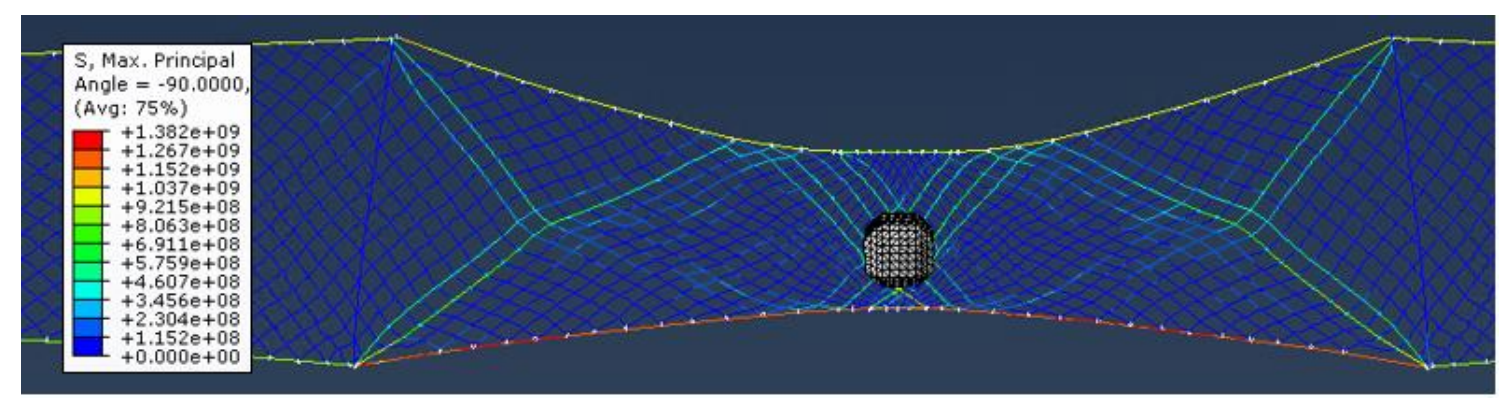

Figure 29. Maximal stress in the central module of the model with brakes.

Although more energy is dissipated by the net and the posts in the model with brakes, the sum of plastic energy of the perimeter and lateral cables, upstream cables, net and posts is not as high as in the case without brakes $(31.75 \mathrm{~kJ})$, as they only sum $21.79 \mathrm{~kJ}$.

A consequence of the inclusion of the brakes is that a difference in the energy components into which the total absorbed energy can be divided is detected, like that obtained due to friction or elastic (recoverable) deformation. This can be more clearly seen in Figure 30.
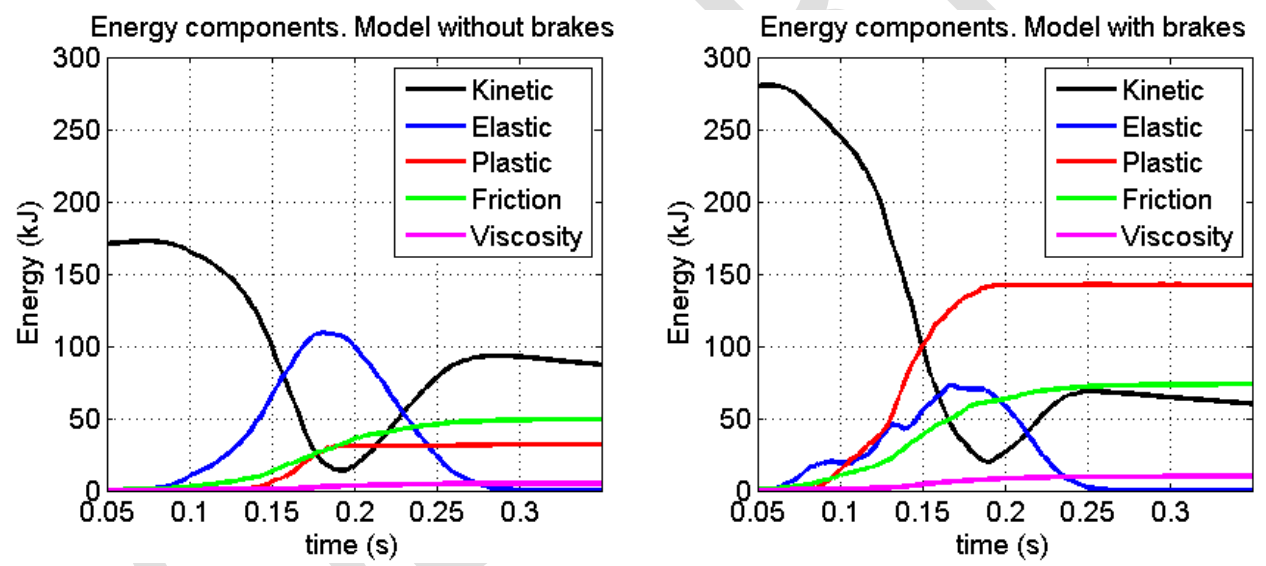

Figure 30. Energy components in model IBT150 with and without the new brake design

The kinetic energy applied to the block (black line of Figure 30), must be compensated by the sum of the elastic deformation (which is the only recoverable energy), the plastic deformation, the friction component and the viscous component. This last component does not appear in the real tests, since it is the energy dissipated by damping mechanisms corresponding to the bulk viscosity damping included in the model to help its convergence. In any case, the maximum value of the viscous component does not surpass $3.6 \%$ of the total energy. The energy dissipated by friction increases in the model with brakes from $50 \mathrm{~kJ}$ to $74 \mathrm{~kJ}$ due to the higher movement of the net towards the centre that causes its inclusion, enforcing the sliding of the mesh at the edges of the net through the shackles. The energy dissipated by elastic deformation plays an essential role in the retention of the block in the model without brakes, and this energy is mainly located along the perimeter and lateral cables. However, when the brakes are added to the model the energy absorbed by elastic deformation is not so relevant -its maximum value is 40 kJ lower-, and the main energy component involved in energy dissipation was by plastic dissipation of the elements of the barrier. 


\section{Conclusions and future work}

A complete brake design process has been described for use in rockfall protection barriers. The process was carried out combining experimental tests and numerical simulation, and the following conclusions were found:

- Dynamic tests show that the brake is adequate for its installation since the behaviour is as expected in working conditions. The difference between the energy applied to the test and the energy obtained integrating the graph of load vs compression of the wire sensors is attributable to the elastic and plastic deformation of the cable, the rebound of the block caused by the recovery of the elastic deformation of the cable and the friction between the cables and the rest of the components.

- The aim of the brake design is achieved, since regular results are obtained in repetitive quasi-static experimental tests on the three brakes tested. Loads in dynamic tests never surpass the curve of the quasi-static one, preventing undesirable effects in real performance.

- Two numerical models of a 2-tube brake of $101.5 \mathrm{~mm}$ diameter and $5 \mathrm{~mm}$ thickness were successfully simulated, with the only difference of taking rigid plugs in the first attempt and elastoplastic plugs in the second model. Both models presented a very good fit, with an error on energy of $6.2 \%$ and $3.5 \%$, respectively.

- The numerical model with elastoplastic plugs was used to evaluate the distribution of energy absorbed by each component. From that study, it can be clearly seen that the main dissipation mechanism is due to the plastic deformation of the tubes, which is progressively increasing. At the end of the test, the energy of the tubes reduces its slope because they are almost completely compressed and the cables start to deform elastically and plastically. Plugs only deform around the holes, specifically on its external part due to the eccentricity of the brake, and they only absorb 0.4kJ.

- The model with rigid plugs was used to study the suitability of other brake dimensions, since a reduction of the computational time of $86 \%$ with respect to the model with elastoplastic plugs was reached, with a very low difference on the load-displacement curve. Using this model, a diameter of $133 \mathrm{~mm}$ and $8 \mathrm{~mm}$ thickness was found to be the best option, combining maximum energy in absolute terms and efficiency in terms of energy per unit of mass.

- The inclusion of 6-tube brakes in a barrier with the geometry of IBT-150 increases the resistance of the barrier by $105 \mathrm{~kJ}$. The failure point appeared in one of the perimeter cables and the brakes did not wear out its full capacity.

- The energy absorbed by plastic deformation is differently distributed among all the parts of the barrier depending on the inclusion or not of the new design of brakes. This difference in energy allocation will occur with any change made in any component of any barrier, and it is considered a relevant barrier characteristic that should be studied in every barrier and component design. In this specific case, the most relevant results are that, in the model with brakes, the net increased its plastic energy absorption in a $5.41 \%$, whilst the perimeter and lateral cables decreased this value in an $86.58 \%$. The elements with a higher percentage of plastic energy absorption were the brakes, with an $84.39 \%$.

All the work presented here was carried out with 16-mm diameter cables. For future research, cables of greater dimensions should be used. Whilst the breaking load of a 16-mm diameter cable is $200 \mathrm{kN}$, this value is $62.5 \%$ higher ( $325 \mathrm{kN}$ ) simply increasing the diameter by $4 \mathrm{~mm}$. As 
ascertained in this work, the brake does not break at the ultimate cable strength due to the friction mechanism and the eccentricity, but this happens at $85 \%$ of the maximum cable load. If this value were extrapolated to the case of using a $20-\mathrm{mm}$ cable on a brake, the maximum load value of the brake would be $276 \mathrm{kN}$. Knowing this, the 10-mm diameter tubes could compress as much as possible, making them more efficient by taking advantage of all their energyabsorption capacity. The increase in the cable diameter would also imply an increase by some millimetres of the hole's dimensions, slightly reducing the activation force and the energy absorption. The dependence of the load-displacement curve on the holes' dimensions has not been considered in this work and should be investigated as future work.

Despite the brake shows completely regular behaviour looking at the quasi-static forcedisplacement graphs, the results of the dynamic tests seem to be more irregular and could have certain dependency on the impact speed or other dynamic variables. In order to get a better knowledge of this, future work should also be focused on performing new dynamic tests using different speeds and attempting to fully compress the brakes. In that way, improvements of the brakes could be done derived of the results of this tests. At last, for the dynamic tests, a new location of the load sensors above the brake instead of below is proposed in order to avoid the undesirable movement of the sensor that could increase the dispersion of the results.

\section{Acknowledgements}

The authors would like to thank the company Inchalam of the Bekaert group for the information provided, as well as LADICIM and LABEST for enabling the performance of a large part of the experimental tests in their facilities.

\section{Bibliography}

[1] Volkwein A, Schellenberg K, Labiouse V, Agliardi F, Berger F, Bourrier F, Dorren LKA, Gerber W, Jaboyedo M. Rockfall characterisation and structural protection-a review. Nat Hazards Earth Syst Sci 2011; 11:2617-2651. https://doi.org/10.5194/nhess-11-2617-2011, 2011

[2] S.Q. Shi, M. Wang, X.Q. Peng, et al. "A New-Type Flexible Rock-Shed Under the Impact of Rock Block: Initial Experimental Insights." Natural Hazards and Earth System Sciences 13, no. 12 (2013): 3329-3338.

[3] Castanon-Jano L, Blanco-Fernandez E, Castro-Fresno D, Ferreño D. Use of explicit FEM models for the structural and parametrical analysis of rockfall protection barriers, Eng Struct 2018; 166:212-226. https://doi.org/10.1016/j.engstruct.2018.03.064.

[4] Escallón JP, Wendeler C (2013) Numerical simulations of quasi-static and rockfall impact tests of ultra-high strength steel wire-ring nets using Abaqus/Explicit. 2013 SIMULIA Community Conference

[5] de Miranda S, Gentilini C, Gottardi G, Govoni L, Mentani A, Ubertini F (2015) Virtual testing of existing semi-rigid rockfall protection barriers. Eng Struct 2015; 85:83-94. http://dx.doi.org/10.1016/j.engstruct.2014.12. 022 
[6] Escallón JP, Wendeler C, Chatzi E, Bartelt P. Parameter identification of rockfall protection barrier components through an inverse formulation. Eng Struct 2014; 77:1-16. http://dx.doi.org/10.1016/j.engstruct.2014.07.019.

[7] Castanon-Jano L, Blanco-Fernandez E, Castro-Fresno D, Ballester-Muñoz F. Energy Dissipating Devices in Falling Rock Protection Barriers (2017) Rock Mech Rock Eng 2017; 50 (3):603-619. http://dx.doi.org/10.1007/s00603-016-1130-x

[8] Trad A. Analyse du Comportement et Mode'lisation de Structures Souples de Protection: le cas des Ecrans de Filets Pare-Pierres sous Sollicitations Statique et Dynamique. PhD thesis 2011, Institut National des Sciences Appliquées de Lyon

[9] Fulde M, Müller M. Development of a modular brake element for the use in modern rockfall catchment fences. 64th Highway Geology Symposium Highway Geology Symposium (September, 2013).

[10] Peila D, Pelizza S, Sassudelli F. Evaluation of behaviour of rockfall restraining nets by full scale tests. Rock Mech Rock Eng 1998; 31(1):1-24. http://dx.doi.org/10.1007/s006030050006

[11] Tran PV, Maegawa K, Fukada S. Experiments and dynamic finite element analysis of a wirerope rockfall protective fence. Rock Mech Rock Eng 2013; 46 (5): 1183-1198. http://dx.doi.org/10.1007/s00603-012-0340-0

[12] Wang M, Shi SQ, Cui LM, Yang YK. Mechanical performance analysis on U-brake energy dissipator used in passive protection nets. Engineering Mechanics 2016; 33 (6): 114-119, 145.

[13] Wang W, Shi S, Wang G. Comparative study on mechanical properties of a tube-crushing dissipator and a symmetric tube-crushing dissipator. Advances in Civil Engineering, 2019, Article ID 8156432. http://dx.doi.org/10.1155/2019/8156432

[14] Castro-Fresno D, Del Coz Díaz J.J, Garcia Nieto P.J, Norambuena Contreras J. Comparative analysis of mechanical tensile tests and the explicit simulation of a brake energy dissipater by $\begin{array}{llllll}\text { FEM. INT } J \text { NONLIN SCI NUM 2009; } 10 & \text { (8):1059-1085. }\end{array}$ https://doi.org/10.1515/IJNSNS.2009.10.8.1059

[15] Smith D, Duffy J. Field test and evaluation of rockfall restraining nets, final report. 1990. California Department of Transportation Materials and Research. USA

[16] Yu Z, Zhao L, Liu Y, Zhao S, Xu H, Chan S. Studies on flexible rockfall barriers for failure modes, mechanisms and design strategies: a case study of Western China. Landslides 2018: 116. https://doi.org/10.1007/s10346-018-1093-y

[17] EOTA. European Assesment Document-EAD 340059-00-0106. Falling Rock Protection Kits. July 2018.

[18] Castro Fresno D, Blanco Fernandez L, Castanon-Jano L, Alonso-Estebanez A. 2018. International Patent WO 201S/215216 A1

[19] ANSYS $^{\circledR}$ Academic Research Mechanical, Release 17.0

[20] Trad A, Limam A, Robit P. Real scale experiments on rockfall protection barriers. Appl Mech Mater 2011;82:734-739. https://doi.org/10.4028/ www.scientific.net/AMM.82.734 
[21] Blanco-Fernandez E, Castro-Fresno D, Del Coz Díaz JJ, Díaz J. Field measurements of anchored flexible systems for slope stabilisation: evidence of passive behaviour. Eng Geol 2013; 153:95-104. https://doi.org/10.1016/j.enggeo.2012.11.015

[22] DEWE-43A Technical Reference Manual. 2017.Dewesoft. Available: https://d36j349d8ram96.cloudfront.net/3/6/DEWE-43 user\%20manual.pdf

[23] Abaqus Analysis User's Manual, Version 6.13 Dassault Systems Simulia Corp, Providence, RI. 